\title{
Expression of Ribonucleotide Reductase Subunit-2 and Thymidylate Synthase Correlates with Poor Prognosis in Patients with Resected Stages I-III Non-Small Cell Lung Cancer
}

\author{
Francesco Grossi, ${ }^{1}$ Maria Giovanna Dal Bello, ${ }^{1}$ Sandra Salvi, ${ }^{2}$ Roberto Puzone, \\ Ulrich Pfeffer, ${ }^{4}$ Vincenzo Fontana, ${ }^{5}$ Angela Alama, ${ }^{1}$ Erika Rijavec, ${ }^{1}$ Giulia Barletta, \\ Carlo Genova, ${ }^{1}$ Claudio Sini, ${ }^{1}$ Giovanni Battista Ratto, ${ }^{6}$ Mario Taviani, ${ }^{6}$ \\ Mauro Truini, ${ }^{2}$ and Domenico Franco Merlo ${ }^{5}$ \\ ${ }^{1}$ Lung Cancer Unit, IRCCS A.O.U San Martino IST-Istituto Nazionale per la Ricerca sul Cancro, Largo Rosanna Benzi 10, \\ 16132 Genova, Italy \\ ${ }^{2}$ Pathology and Cytohistology Division, IRCCS A.O.U San Martino IST-Istituto Nazionale per la Ricerca sul Cancro, \\ Largo Rosanna Benzi 10, 16132 Genova, Italy \\ ${ }^{3}$ Clinical Epidemiology Division, IRCCS A.O.U San Martino IST-Istituto Nazionale per la Ricerca sul Cancro, \\ Largo Rosanna Benzi 10, 16132 Genova, Italy \\ ${ }^{4}$ Integrated Molecular Pathology Division, IRCCS A.O.U San Martino IST-Istituto Nazionale per la Ricerca sul Cancro, \\ Largo Rosanna Benzi 10, 16132 Genova, Italy \\ ${ }^{5}$ Epidemiology, Biostatistics and Clinical Trials Division, IRCCS A.O.U San Martino IST-Istituto Nazionale per la Ricerca sul Cancro, \\ Largo Rosanna Benzi 10, 16132 Genova, Italy \\ ${ }^{6}$ Thoracic Surgery Division, IRCCS A.O.U San Martino IST-Istituto Nazionale per la Ricerca sul Cancro, Largo Rosanna Benzi 10, \\ 16132 Genova, Italy
}

Correspondence should be addressed to Francesco Grossi; francesco.grossi@hsanmartino.it

Received 10 August 2015; Revised 5 October 2015; Accepted 7 October 2015

Academic Editor: Robert Pichler

Copyright (c) 2015 Francesco Grossi et al. This is an open access article distributed under the Creative Commons Attribution License, which permits unrestricted use, distribution, and reproduction in any medium, provided the original work is properly cited.

Biomarkers can help to identify patients with early-stages or locally advanced non-small cell lung cancer (NSCLC) who have high risk of relapse and poor prognosis. To correlate the expression of seven biomarkers involved in DNA synthesis and repair and in cell division with clinical outcome, we consecutively collected 82 tumour tissues from radically resected NSCLC patients. The following biomarkers were investigated using IHC and qRT-PCR: excision repair cross-complementation group 1 (ERCC1), breast cancer 1 (BRCA1), ribonucleotide reductase subunits M1 and M2 (RRM1 and RRM2), subunit p53R2, thymidylate synthase (TS), and class III beta-tubulin (TUBB3). Gene expression levels were also validated in an available NSCLC microarray dataset. Multivariate analysis identified the protein overexpression of RRM2 and TS as independent prognostic factors of shorter overall survival (OS). KaplanMeier analysis showed a trend in shorter OS for patients with RRM2, TS, and ERCC1, BRCA1 overexpressed tumours. For all of the biomarkers except TUBB3, the OS trends relative to the gene expression levels were in agreement with those relative to the protein expression levels. The NSCLC microarray dataset showed RRM2 and TS as biomarkers significantly associated with OS. This study suggests that high expression levels of RRM2 and TS might be negative prognostic factors for resected NSCLC patients.

\section{Introduction}

Only $30-40 \%$ of new patients diagnosed with NSCLC have disease confined to the thorax. The standard of care for patients with early-stage NSCLC is surgical resection, but 50$60 \%$ of patients with local disease relapse within two years [1].

The 5-year overall survival (OS) by pathologic stage is, respectively, $73 \%$ and $54 \%$ for stages IA and IB, $48 \%$ and 
$38 \%$ for stages IIA and IIB, and $25 \%$ and $19 \%$ for stages IIIA and IIIB [2]. Because of this high and rapid recurrence rate, adjuvant chemotherapy after surgery is recommended for selected stages IB, II, and III patients $[3,4]$.

The only criterion currently used in standard practice to estimate prognosis is disease stage. Therefore, the discovery of prognostic markers that are different and independent of tumour stage represents a high medical need that has been unmet thus far.

In this study, we evaluated the protein and mRNA expression levels of seven biomarkers involved in DNA repair (ERCC1, BRCA1, RRM1, RRM2, and p53R2), DNA synthesis (TS), and cellular division (TUBB3) to test the hypothesis that these biomarkers could act as prognostic factors in radically resected NSCLC patients. We also investigated the association of gene expression with OS using a large publicly available NSCLC microarray dataset [5].

Briefly, ERCC1 is a crucial component of the nucleotide excision repair (NER) pathway that repairs DNA damage following exposure to platinum agents. The IALT-Bio study, using an IHC-based $\mathrm{H}$-scoring system, showed that, in patients who did not receive adjuvant chemotherapy, the 5year survival rate among ERCC1-positive patients was higher (46\%) compared to ERCC1-negative patients $(39 \%)(p=$ 0.009), demonstrating that ERCC1 expression levels may be a valuable indicator of prognosis [6]. Subsequently, the same authors [7] investigated the tumour specimens from the IALT-Bio study for ERCC1 expression using a fluorescencebased automated scoring system (AQUA). The difference in OS for patients with high and low ERCC1 expression had a similar trend as that previously reported with IHC in the control group (untreated patients), although the difference was not statistically significant. These conflicting findings place doubts on the role of ERCC1 in resected NSCLC patients' outcome justifying further investigations.

BRCA1 has multiple roles not only in DNA damage repair but also in cell cycle regulation, transcriptional control, ubiquitination, and apoptosis [8]. Rosell et al. [9] evaluated the association between BRCA1 mRNA expression and survival in radically resected NSCLC patients and demonstrated that high expression levels were strongly associated with poor survival.

Another important molecule involved in DNA synthesis and repair is the enzyme ribonucleotide reductase (RR) that catalyses the conversion of ribonucleotides into deoxyribonucleotides [10]. RR consists of three subunits, RRM1, RRM2, and p53R2. RRM1 contains enzymatically active sites and binding sites for allosteric effectors. The p53R2 gene contains a p53-binding sequence and can functionally substitute for RRM2 because the genes are homologous (80\%) and both possess a diiron-tyrosyl radical cofactor that is essential for enzyme activity [11]. RRM1 interacts with either RRM2 or p53R2 to become the catalytically active form of eukaryotic RR. The prognostic role of p53R2 in stages I-III NSCLC patients was investigated by Uramoto et al. [12] who concluded that p53R2 did not play an important prognostic role and that the pathway mediated by $\mathrm{p} 53 \mathrm{R} 2$ may be responsible for controlling the growth of lung cancer. Conversely, Hsu et al. $[13,14]$ showed that the presence of
p53R2 protein is a favorable prognostic factor in early-stage lung cancer. There is limited information concerning the prognostic role of RRM2 and RRM1 mRNA expression in human lung tumours. Loss of heterozygosity (LOH) for the RRM1 gene has been correlated with poor survival in resected NSCLC patients [15] and has been found to be a significant adverse prognostic factor. Preclinical studies have revealed a potential prognostic role for RRM2 demonstrating that cells that overexpress RRM2 mRNA exhibit enhanced cellular invasiveness [16] through activation of nuclear factor $\mathrm{kB}$ (NF- $\kappa \mathrm{B})$ and increased matrix metalloproteinase-9 (MMP-9) expression [17].

Microtubules consist of $\alpha$-tubulin and $\beta$-tubulin dimers and are critical for cell growth and division. The tubulins can exist in various isotypes and TUBB3 is one of the six human isotypes that comprise microtubules. Sève et al. [18, 19] conducted a retrospective study to explore the potential of this biomarker as a prognostic or predictive factor in advanced NSCLC patients and provided strong evidence that the overexpression of TUBB3 has a predictive value for paclitaxel therapy but is not itself a prognostic factor. In contrast, Reiman et al. [20] conducted a meta-analysis considering the prognostic and predictive value of TUBB3 in resected NSCLC patients enrolled in four randomized controlled trials of adjuvant chemotherapy, showing a prognostic effect of high TUBB3 expression while they were unable to demonstrate its predictive role in adjuvant setting.

Finally, TS is an essential enzyme for de novo DNA synthesis and DNA damage repair and is a key target for cancer chemotherapeutic agents. Higher TS mRNA expression levels have been shown in squamous cell carcinoma compared to adenocarcinomas [21]. Nakagawa et al. [22] demonstrated that TS status is a significant prognostic factor in resected adenocarcinoma of the lung suggesting that patients with high TS expression levels have poor survival. However, further evidence is needed to confirm the clinical importance of TS expression. The aim of this study was to correlate the gene and protein expression levels of these seven biomarkers with clinicopathologic features and clinical outcome of patients with resected NSCLC to investigate their possible prognostic role.

\section{Materials and Methods}

2.1. Study Population. Tumour samples from 82 consecutive patients with stages I-III NSCLC who had undergone surgical resection at the National Institute for Cancer Research (Genova, Italy) between July 2005 and March 2007 were examined for gene and protein expression after obtaining approval from the Institutional Review Board. The study was done in compliance with the principle of the Declaration of Helsinki and written informed consent for use of tissue was acquired from patients at the time of first outpatient visit. All tumours were curatively resected without microscopic residual tumours by lobectomy, bilobectomy, or pneumonectomy. None of the patients received adjuvant radiation or chemotherapy. Each patient's vital status was ascertained across the follow-up period of July 2005-July 2010, and 
TABLE 1: Patients and tumours characteristics.

\begin{tabular}{lc}
\hline Characteristics & Number \\
\hline Number of patients & 82 \\
Median age at diagnosis (Y, median range) & $69(47-32)$ \\
Gender & \\
Female & $20(24 \%)$ \\
Male & $62(76 \%)$ \\
Smoking habit & \\
Never-smokers & $6(7 \%)$ \\
Ex-smokers & $22(27 \%)$ \\
Smokers & $54(66 \%)$ \\
Histological type & \\
Adenocarcinoma & $50(61 \%)$ \\
Large cell carcinoma & $3(4 \%)$ \\
Squamous cell carcinoma & $28(34 \%)$ \\
Other & $1(1 \%)$ \\
Pathological stage & \\
IA & $23(28 \%)$ \\
IB & $21(26 \%)$ \\
IIA & $4(5 \%)$ \\
IIB & $11(13 \%)$ \\
IIIA & $16(20 \%)$ \\
IIIB & $7(8 \%)$ \\
Surgery & \\
Bilobectomy & $11(13 \%)$ \\
Lobectomy & $70(85 \%)$ \\
Pneumonectomy & $1(1 \%)$ \\
\hline
\end{tabular}

survival time was computed from the date of surgery to death or the end of follow-up for patients that remained alive.

Patients and tumour characteristics are shown in Table 1.

2.2. Tissue Microarrays Construction and Immunohistochemistry. Tumour tissue microarrays (TMAs) and immunohistochemistry (IHC) were performed as previously reported $[23,24]$, using 82 Formalin Fixed Paraffin Embedded (FFPE) primary NSCLC samples. Slides of tumour samples stained with hematoxylin and eosin were independently reviewed by two pathologists (M.T. and S.S.), and representative areas were marked. Core tissue biopsy specimens $(2 \mathrm{~mm}$ in diameter) were obtained in duplicate from each donor tumour block and placed in a new recipient paraffin block (tissue array block) with a manual tissue microarrayer (Galileo TMA CK 3500, Bio Rep, Milano). Sections $(3 \mu \mathrm{m})$ were cut from each tissue array block, placed on slides, deparaffinised, dehydrated, and used for immunohistochemical analysis. TMA IHC was performed using the automatic immunostainer Benchmark XT (Ventana Medical Systems, SA Strasbourg, France). Briefly, antigen-retrieval was performed using citrate buffer ( $\mathrm{pH} 6$ ) at $90^{\circ} \mathrm{C}$ for 30 minutes. Then, the slides were incubated in primary antibody for 1 hour at $37^{\circ} \mathrm{C}$ followed by the addition of the polymeric detection system Ventana Medical System Ultraview Universal DAB Detection Kit. Finally, the slides were counterstained with modified Gill's hematoxylin and mounted in Eukitt.
In detail, the primary antibodies used and the positive control for each biomarker were as follows:

(i) BRCA1, clone GLK-2 (Diagnostic Bio System); epitope: peptide corresponding to amino acids 18391863 of the c-terminus of BRCA1; species: mouse; dilution $1: 100$, visualization: nuclear, nuclear/cytoplasmatic; and positive control: ovarian carcinoma.

(ii) p53R2, clone p53R2 (Novus Biological); epitope: peptide corresponding to amino acids $2-17$ of p53R2; species: rabbit polyclonal; dilution 1:200; visualization: nuclear; and positive control: lung cancer (normal and tumoural).

(iii) ERCC1, clone 8F1 (Diapath); epitope not determined; species: human and rat; dilution $1: 100$, visualization: nuclear; and positive control: lung cancer (normal and tumoural).

(iv) TS, clone TS 106 (DAKO); epitope: peptide corresponding to amino acids $133-142$ of TS; species: mouse; dilution $1: 10$; visualization: cytoplasmatic, nuclear/perinuclear; and positive control: tonsil and lymph node.

(v) TUBB3, clone MU 177-UC (Biogenex); epitope not available; species: mouse; dilution 1:100; visualization: cytoplasmatic; and positive control: lung cancer (normal and tumoural).

(vi) RRM1, clone NA (Spring); epitope not available; species: rabbit; dilution 1:10; visualization: cytoplasmatic; and positive control: lung cancer (normal and tumoural).

(vii) RRM2, clone 1E1 (Novus Biological); epitope not available; species: mouse; dilution $1: 10$; visualization: cytoplasmatic; and positive control: breast cancer (normal and tumoural).

An appropriate external positive control tissue was used for each staining procedure; the negative control consisted of performing the entire IHC procedure on an adjacent section in the absence of the primary antibody. Stained slides were analysed by two independent observers using an optical microscope (Olympus BX41) with 10x and 40x objectives. Immunoreactivity was graded in the tumours according to the number of immunoreactive cells and/or staining intensity using a scoring system. Regarding TS expression, the immune reaction was graded as negative (score 0 ) or positive, in a semiquantitative, 3-tier system based on the extent of reactivity (score 1, 1-10\% reactivity; score 2, 11-50\% reactivity; and score $3,>50 \%$ reactivity) [21]. Expression of ERCC1 was quantified using a visual grading system based on the extent of staining (percentage of tumour cells) graded on a scale of 0-3 ( $0=$ no staining, $1=$ weak staining, $2=$ moderate staining, and $3=$ strong staining) [25]. Expressions of BRCA1, RRM1, RRM2, p53R2, and TUBB3 were evaluated semiquantitatively based on staining intensity and proportion. The proportion of staining was scored on a scale from 0 to 3 as follows: diffuse, $\geq 50 \%$ positive (score 3 ); regional, $10-49 \%$ positive (score 2 ); focal, 1-9\% (score 1); and negative (score 0 ). In addition, 
the staining intensity was scored from 0 to 3 ( 0 , absent; 1 , weak; 2, moderate; and 3, intense) [26]. A final histochemical score $(H$-score) for each sample was calculated as previously reported [24]. Positive staining (BRCA1, p53R2, and TS) or the median score values (ERCC1, RRM1, RRM2, and TUBB3) were used as cut-off criteria to categorise patients in two groups for statistical analysis.

Representative results of immunohistochemical staining of NSCLC specimens are provided in Figures 1-2.

2.3. Reverse Transcription and $q R T-P C R$. RNA was isolated from the 82 FFPE tumour samples used for the TMA construction using the High Pure FFPE RNA Micro Kit (Roche Applied Science, Mannheim, Germany) with minor modifications. For each FFPE block, a representative H\&E stained section was reviewed by a pathologist to consider the tumour cells content. Whether the neoplastic elements were at least $70 \%$ of the total cell population, the tumour block was considered suitable for the analysis. From each FFPE block, four $10 \mu \mathrm{m}$-thick sections were deparaffinised twice with $1.0 \mathrm{~mL}$ Histo-Clear (National Diagnostics, Atlanta, GA, USA) for $5 \mathrm{~min}$ at room temperature, followed by washing in $1.0 \mathrm{~mL}$ of $100 \%$ ethanol and $70 \%$ ethanol. The tissue pellet was air-dried for $15 \mathrm{~min}$ at $55^{\circ} \mathrm{C}$ and then lysed by incubation overnight with proteinase $\mathrm{K}$ at $55^{\circ} \mathrm{C}$ until the digestion was complete. Genomic DNA contamination was removed using an on-column DNase I treatment. RNA yield and purity were checked with a NanoDrop-1000 Detector (NanoDropTechnologies, Wilmington, NC, USA).

After isolation, one microgram of RNA was reversetranscribed with an engineered version of M-MLV Reverse Transcriptase (SuperScript II RT, Invitrogen, Grand Island, NY, USA) according to the manufacturer's instructions and the resulting cDNA was amplified by the LightCycler 480 Real Time PCR System II (Roche Applied Science). PCR reactions were performed in a final volume of $20 \mu \mathrm{L}$ containing $2 \mu \mathrm{L}$ of cDNA, $10 \mu \mathrm{L}$ of LightCycler 480 SYBR Green I Master Mix (Roche Applied Science), and $4 \mu \mathrm{L}$ of $2 \mu \mathrm{M}$ forward and reverse primers. The thermal profile for the samples amplification included an initial incubation at $95^{\circ} \mathrm{C}$ for 10 minutes for activation of FastStart Taq DNA Polymerase, 45 cycles of denaturation at $95^{\circ} \mathrm{C}$ for 10 seconds followed by annealing at $60^{\circ} \mathrm{C}$, and extension at $72^{\circ} \mathrm{C}$ for 15 seconds. All the samples were amplified in triplicate with appropriate nontemplate controls. Specific forward and reverse primers were designed by Primer3 software (http://bioinfo.ut.ee/primer3-0.4.0/) on the basis of gene sequences obtained from the GenBank. All primers were intron-spanning to avoid genomic DNA contamination and the oligonucleotide sequences are presented in Table 2. The housekeeping genes beta-2-microglobulin (B2M) and beta-glucuronidase (GUSB) were used for their suitability as internal references in clinical lung cancer specimens $[27,28]$. Relative gene expression levels were calculated by the $2^{-\Delta \mathrm{Ct}}$ method (LightCycler $480 \mathrm{SW} 1.5$ ) and samples were normalized for the mean of the two housekeeping genes as measured by analysis with Bestkeeper software (http://www.wzw.tum.de/gene-quantification/bestkeeper.html) [29].
For each biomarker, the median of the gene expression level was used as the cut-off criteria to categorise patients in two groups for statistical analysis.

2.4. DCC NSCLC Microarrays Dataset Retrieval and Analysis. The DCC NSCLC dataset is a microarray data collection obtained from 442 resected tumours from NSCLC patients. Affymetrix UG133a microchip arrays were used, which contain approximately $22 \mathrm{k}$ probes each. The microarray "CEL" files with extensive clinical and pathological data are publicly available [https://array.nci.nih.gov/ caarray/project/details.action?project.id=182]. The full dataset has been published previously [5]. For the analysis, we included 330 patients with stages I-III tumours that had not received any adjuvant therapy. Age at diagnosis, smoking status, and ERCC1, BRCA1, TS, RRM1, RRM2, and TUBB3 gene expressions were retrieved for statistical analysis (probes for p53R2 are not present in the G133a platform). Standard data processing was applied: GCRMA processing of CEL files [30], probe signal filtering, corrections for known bias [31], mean of probe signals related to the same gene, and gene-level normalisation. Patients were categorised in two groups according to the level of gene expression (i.e., $\leq$ and $>$ median value of each biomarker) for statistical analysis.

2.5. Statistical Analysis. The associations between biomarker levels and patient and tumour characteristics were investigated by means of the Mann-Whitney $U$ test. Pearson's correlation coefficient was computed to measure the relationships between protein and mRNA expression levels for each biomarker. The Kaplan-Meier (K-M) product limit estimator was used to generate survival plots and the log-rank test to compare survival distributions. To this aim, survival time was defined as the difference between date of death or date of end of follow-up, whichever came first, and date of radical surgery and was expressed in years. Cox proportional hazards multiple regression analysis of OS was performed to identify biomarkers with a significant prognostic role, adjusted for the effect of patients and tumours characteristics (i.e., age at diagnosis: $\leq 70$ and $>70$ years, smoking habit: ex/neversmoker, current smoker, pathological TNM: stages I, II, and III, and histological type: nonsquamous, squamous). The stepwise backward procedure was used to select variables contributing to the Cox model as allowed by the IBM SPSS [32] statistical software. The $p$ values for variable entry or removal were 0.05 and 0.10 . Hazard ratio (HR) point estimates and 95\% confidence interval (95\% CI) were computed and differences in OS were considered statistically significant at a $p$ value of $<0.05$. The two-sided log-rank and likelihood ratio statistics were computed to test differences between K-M survival probabilities and HRs estimated by Cox regression. All analyses were performed using IBM-SPSS statistical software, version 20, and the Bioconductor libraries [33]. 


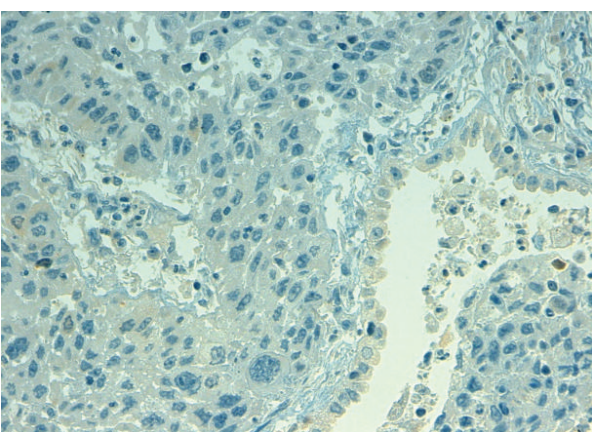

(a)

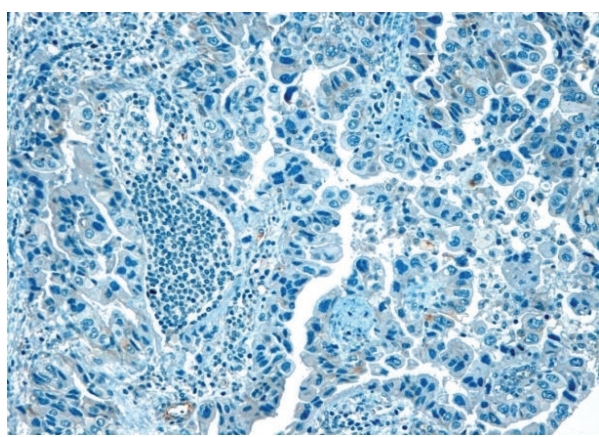

(c)

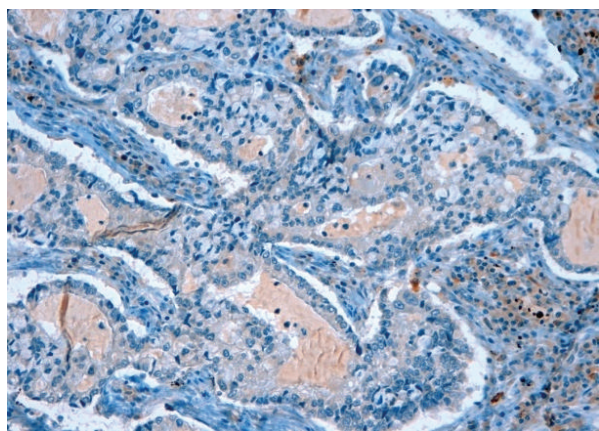

(e)

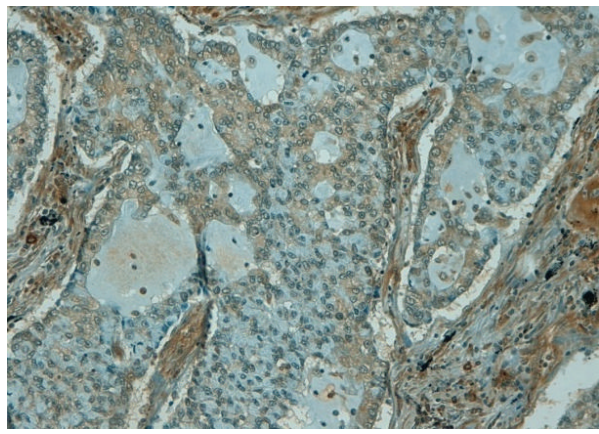

(g)

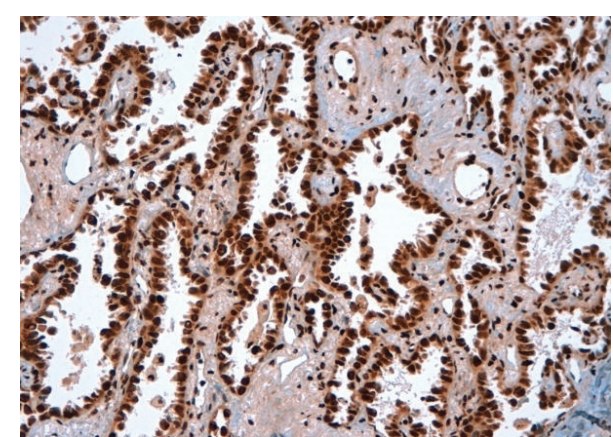

(b)

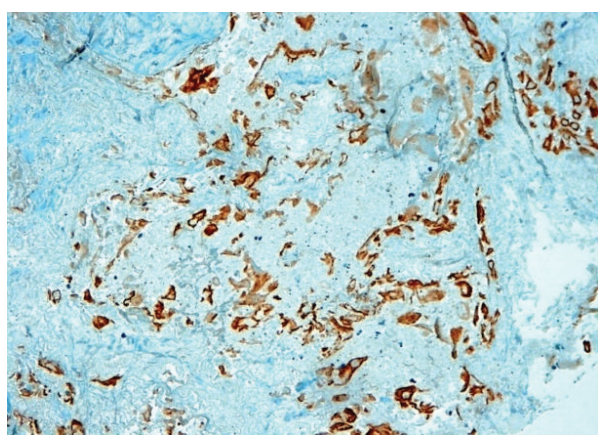

(d)

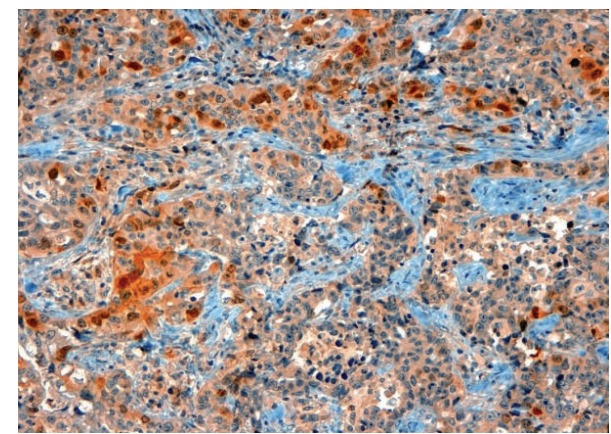

(f)

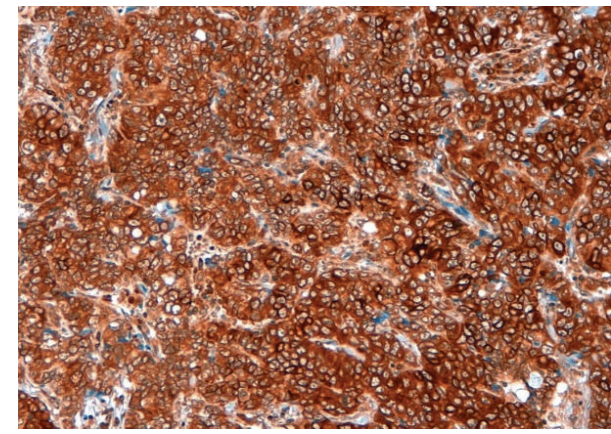

(h)

FIGURE 1: Representative results of IHC staining of NSCLC tumour specimens for ERCC1, BRCA1, TS, and TUBB3. (a) Negative expression of ERCC1 (final score 0), (b) high expression of ERCC1: nuclear staining (final score 3); (c) negative expression of BRCA1 (final score 0), (d) high expression of BRCA1: cytoplasmic staining (final score 2); (e) negative expression of TS (final score 0), (f) high expression of TS: cytoplasmic staining (final score 1) and nuclear staining (final score 2); and (g) negative expression of TUBB3 (final score 0), (h) high expression of TUBB3: cytoplasmic staining (final score 3 ). 


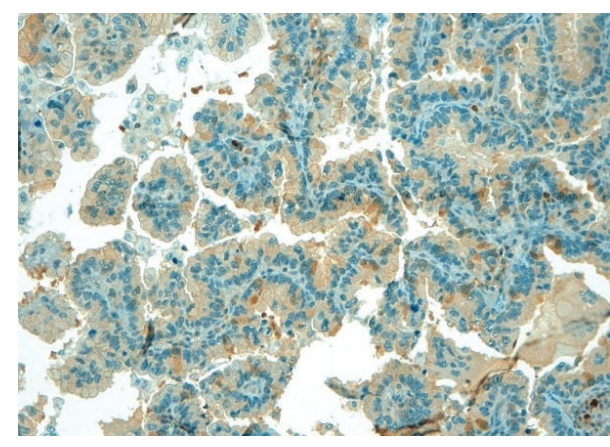

(a)

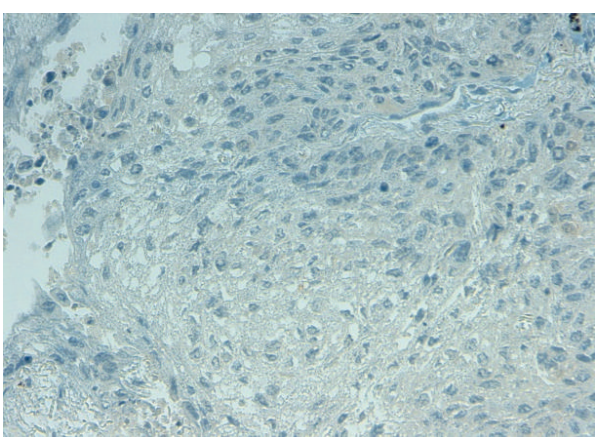

(c)

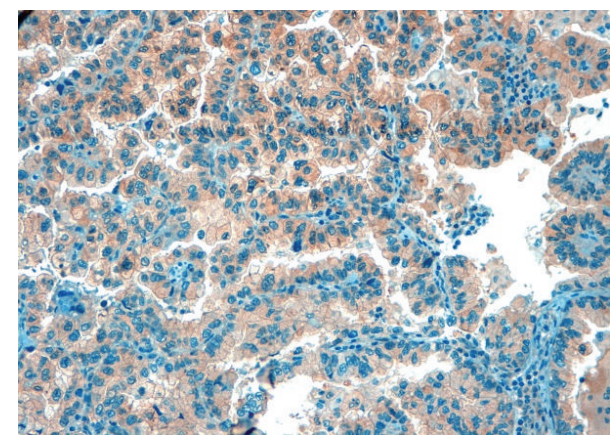

(e)

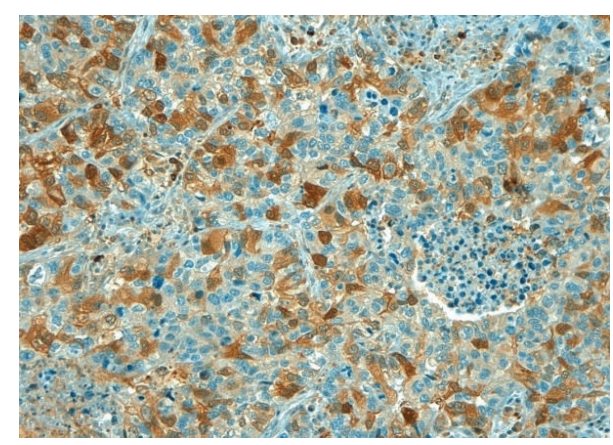

(b)

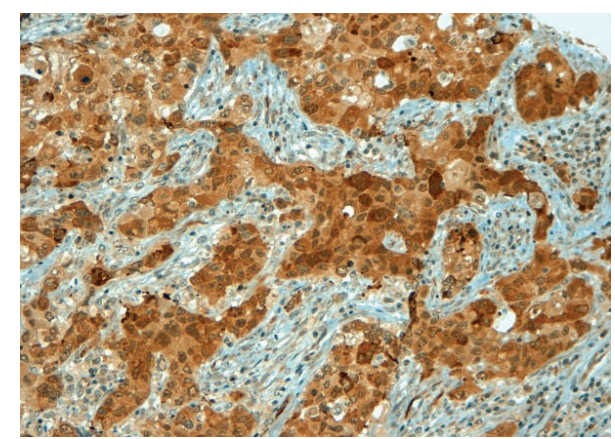

(d)

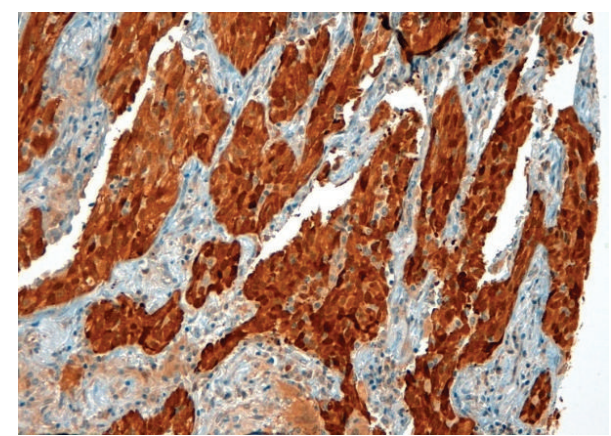

(f)

FIGURE 2: Representative results of IHC staining of NSCLC tumour specimens for RRM2, RRM1, and p53R2. (a) Negative expression of RRM2 (final score 0), (b) high expression of RRM2: cytoplasmic staining (final score 3); (c) negative expression of RRM1 (final score 0), (d) high expression of RRM1: cytoplasmic staining (final score 2); and (e) negative expression of p53R2 (final score 0), (f) high expression of p53R2: nuclear staining (final score 3 ).

\section{Results}

3.1. Associations between the IHC Expression of Biomarkers, Patients, and Clinicopathologic Features and Overall Survival. Among the investigated associations between IHC expression of biomarkers, patients, and clinicopathologic features, only subunit p53R2 was found to be significantly associated with histotype $(p<0.001)$ with more p53R2-positive cases in nonsquamous than in squamous cancer (data not shown). The associations between patient and cancer characteristics, biological markers expression, and OS are shown in Table 3. Among all patients, a total of 37 (45\%) deaths were observed during follow-up. The probability of surviving at 1 year and 2 , 3,4 , and 5 years was $89 \%, 73 \%, 65 \%, 56 \%$, and $54 \%$, respectively. Pathological TNM was the only variable statistically associated with OS in univariate analysis (stage II, $\mathrm{HR}=2.81$, 95\% CI $=1.18-6.69$; stage III, $\mathrm{HR}=4.44$, 95\% CI $=2.08-$ 9.46, $p<0.001$ ) (Table 3). K-M estimated mean survival time was 4.47 years for stage I patients (median survival time not reached), 3.12 years (median 2.69 years) for stage II patients, and 3.70 years (median 1.80 years) for stage III patients (data not shown). K-M analysis showed that despite the lack of statistical significance, patients with lower RRM2 expression (i.e., $\leq 140)$ survived longer $(\mathrm{HR}=1.84$; 95\% CI $=0.95-3.56)$ than patients with higher RRM2 expression (Table 3, Figure 3). The median survival was not reached for RRM2 $\leq 140$ and was 3.7 years for RRM2 > 140. There was a trend towards longer survival for BRCA1-, ERCC1-, and TS-negative patients and for p53R2- and TUBB3-positive patients (Figure 3 ). 

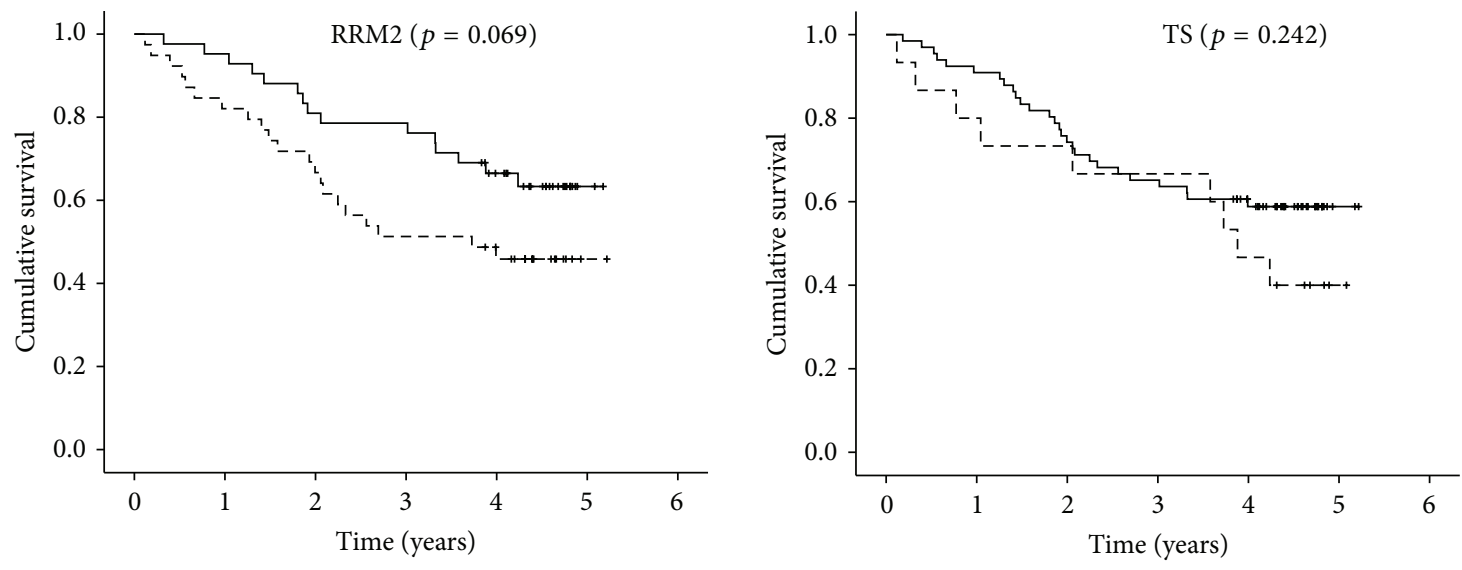

$\neg$ RRM2 $\leq 140$ (median $H$-score)

- 5 . RRM2 > 140 (median $H$-score)

+ RRM2 $\leq 140$-censored

+ RRM2 > 140-censored

(a)

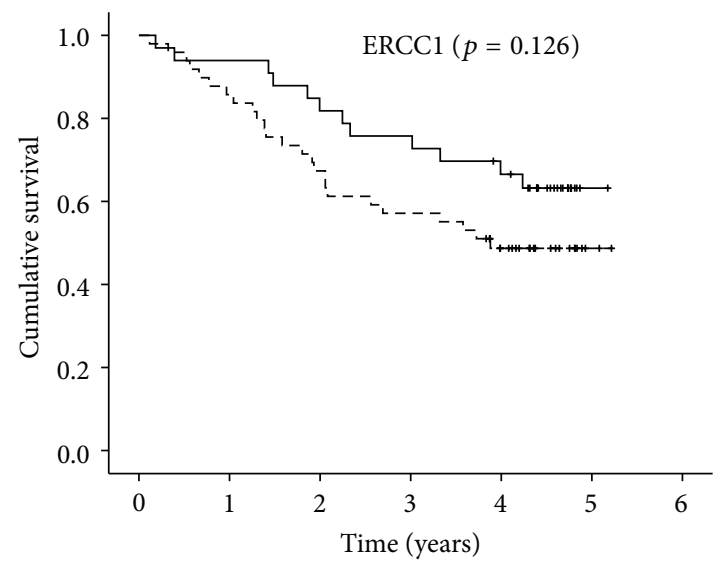

$\neg$ Negative

$-5 ?$ Positive

+ Negative-censored

+ Positive-censored

(b)

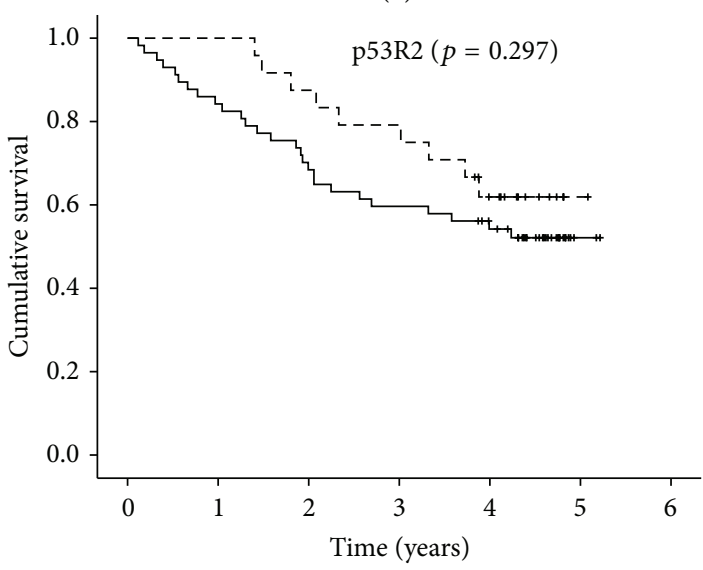

$\neg \leq 140$ (median $H$-score)

$-\neg>140$ (median $H$-score)

$+\leq 140$-censored

$+>140$-censored

(c)

$\neg$ Negative

$-\neg$ ? Positive

+ Negative-censored

+ Positive-censored

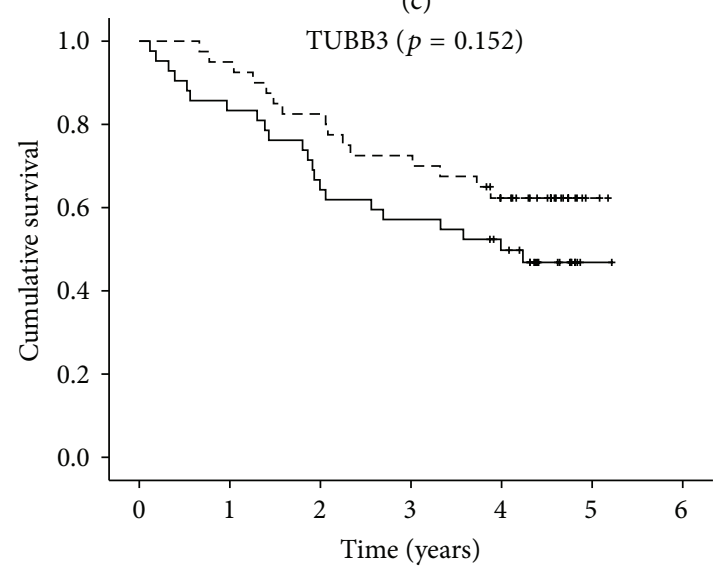

(d)

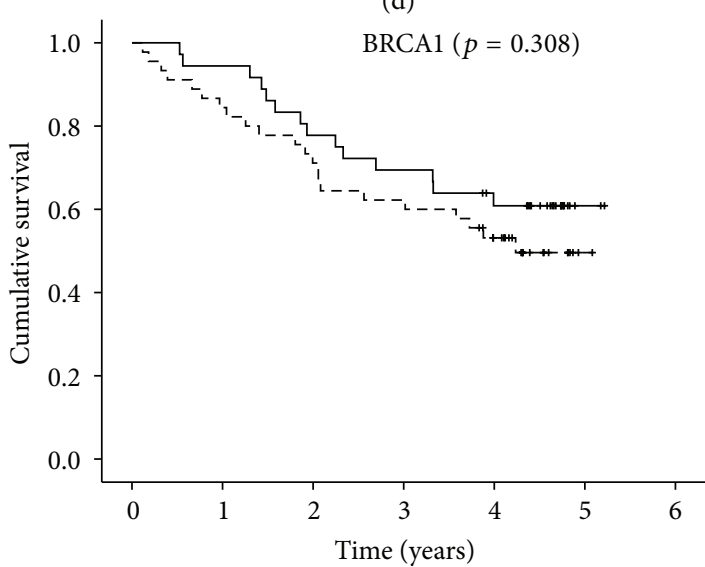

$\neg \leq 60$ (median $H$-score)
$-\neg>60$ (median $H$-score)
$+\leq 60$-censored
$+\quad>60$-censored

$\neg$ Negative

- 5 . Positive

+ Negative-censored

+ Positive-censored

(e)

Figure 3: Continued. 


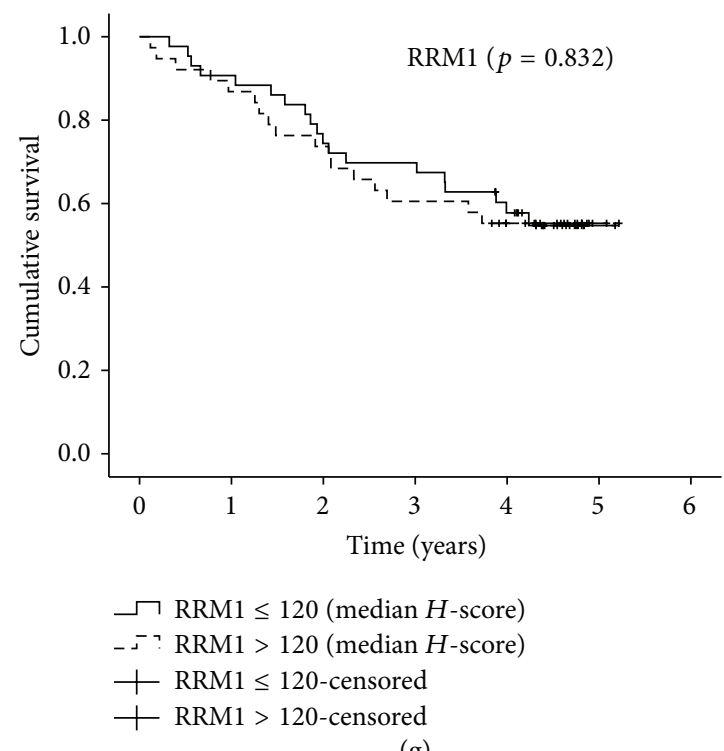

(g)

FIGURE 3: Kaplan-Meier estimates of overall survival according to the protein expression levels of (a) RRM2, (b) TS, (c) ERCC1, (d) p53R2, (e) TUBB3, (f) BRCA1, and (g) RRM1 in the overall population.

TABLE 2: PCR primer sequences.

\begin{tabular}{llcll}
\hline Gene & & Accession number & Primer & Amplicon length \\
\hline B2M & Beta-2-microglobulin & NM_004048 & $\begin{array}{l}\text { Frw TGA CTT TGT CAC AGC CCA AG } \\
\text { Rev AGC AAG CAA GCA GAA TTT GG }\end{array}$ \\
\hline GUSB & Beta-glucuronidase & NM_000181 & $\begin{array}{l}\text { Frw GCC TGT GAC CTT TGT GAG C } \\
\text { Rev GTG CCC GTA GTC GTG ATA CC }\end{array}$ \\
\hline BRCA1 & Breast cancer 1, early onset & NM_007294 & $\begin{array}{l}\text { Frw TCA GCT TGA CAC AGG TTT GG } \\
\text { Rev TCT GTA GCC CAT ACT TTG GAT G }\end{array}$ \\
\hline ERCC1 & $\begin{array}{l}\text { Excision repair cross-complementing } \\
\text { rodent repair deficiency }\end{array}$ & NM_001166049 & $\begin{array}{l}\text { Frw AAT GTG CCC TGG GAA TTT G } \\
\text { Rev TAG TCT GGG TGC AGG TTG TG }\end{array}$ \\
\hline RRM1 & Ribonucleotide reductase subunit M1 & NM_001033 & $\begin{array}{l}\text { Frw GAG GAA TTG GTG TTG CTG TG } \\
\text { Rev ACT CTC AGC ATC GGT ACA AGG }\end{array}$ \\
\hline RRM2 & Ribonucleotide reductase subunit M2 & NM_001034 & $\begin{array}{l}\text { Frw TGA ACT GAA GAT GTG CCC TTA C } \\
\text { Rev TTA CGG ACA ATT CAT GGT GTG }\end{array}$ \\
\hline P53R2 & Ribonucleotide reductase subunit M2B & NM_001172477 & $\begin{array}{l}\text { Frw TCT CCC TCA CTG GAA CAA GC } \\
\text { Rev AAC CTG CAC CTC CTG ACT AAA G }\end{array}$ \\
\hline TUBB3 & Tubulin, beta-3 & NM_001197181 & $\begin{array}{l}\text { Frw GAA GCC AGC AGT GTC TAA ACC } \\
\text { Rev GGA GGA CGA GGC CAT AAA TAC }\end{array}$ \\
\hline TS & Thymidylate synthase & $\begin{array}{l}\text { Frw CGG TGT GCC TTT CAA CAT C } \\
\text { Rev TGT GCA TCT CCC AAA GTG TG }\end{array}$ \\
\hline
\end{tabular}

The multivariate Cox proportional hazards model (Table 3) identified pathologic stage (stage II, HR $=3.51,95 \%$ $\mathrm{CI}=1.35-9.07$; stage III, $\mathrm{HR}=6.54,95 \% \mathrm{CI}=2.86-14.9$, $p<0.001)$ and the overexpression of RRM2 (HR = 2.26; $95 \% \mathrm{CI}=1.08-4.74 ; p=0.031)$ and $\mathrm{TS}(\mathrm{HR}=2.93 ; 95 \% \mathrm{CI}$ $=1.16-7.42 ; p=0.023)$ as independent prognostic factors for OS. Additionally, ERCC1 was found to be associated with shorter survival ( $\mathrm{HR}=2.08 ; 95 \% \mathrm{CI}=0.97-4.44 ; p=0.059)$ but failed to reach statistical significance $(p=0.059)$. Neither
RRM1, p53R2, TUBB3, and BRCA1 expression nor gender, age at diagnosis, smoking habits, and histological type were associated with OS.

3.2. mRNA Expression of Biological Markers and Clinical Outcome. The Mann-Whitney $U$ test showed that there was no association between age, gender, pathological stage, cancer histology, or smoking habits and mRNA levels for all biomarkers analysed (data not shown). Analysis of the 
TABLE 3: Patients characteristics, clinicopathologic features, and IHC analysis: association with OS. Results from Kaplan-Meier univariate and Cox multiple regression analyses.

\begin{tabular}{|c|c|c|c|c|c|c|c|c|c|c|}
\hline \multirow{3}{*}{ Covariates } & \multirow{3}{*}{$N$} & \multicolumn{3}{|c|}{ 5-year survival } & \multicolumn{3}{|c|}{ Kaplan-Meier } & \multicolumn{3}{|c|}{ Cox regression $^{\mathrm{d}}$} \\
\hline & & \multicolumn{2}{|c|}{ Deaths } & \multirow{2}{*}{$\begin{array}{c}\mathrm{SP}^{*} \\
\%\end{array}$} & \multirow[b]{2}{*}{ HR } & \multirow[b]{2}{*}{$95 \% \mathrm{CI}$} & \multirow[b]{2}{*}{$p$ value $^{\mathrm{b}}$} & \multirow[b]{2}{*}{ HR } & \multirow[b]{2}{*}{$95 \% \mathrm{CI}$} & \multirow[b]{2}{*}{$p$ value $^{\mathrm{e}}$} \\
\hline & & $n$ & $\%$ & & & & & & & \\
\hline Gender & & & & & & & 0.967 & & & 0.611 \\
\hline Female & 20 & 9 & 45.0 & 54.6 & 1 & & & 1 & & \\
\hline Male & 62 & 28 & 45.2 & 54.2 & 1.12 & $0.51-2.47$ & & 1.28 & $0.50-3.30$ & \\
\hline Age at diagnosis & & & & & & & 0.850 & & & 0.619 \\
\hline$\leq 70$ years & 46 & 20 & 43.5 & 56.5 & 1 & & & 1 & & \\
\hline$>70$ years & 36 & 17 & 47.2 & 50.6 & 1.06 & $0.55-2.03$ & & 1.22 & $0.56-2.66$ & \\
\hline Smoking habit & & & & & & & 0.066 & & & 0.091 \\
\hline Ex/never-smoker & 28 & 9 & 32.1 & 67.2 & 1 & & & 1 & & \\
\hline Current smoker & 54 & 28 & 51.9 & 47.7 & 1.99 & $0.94-4.24$ & & 1.98 & $0.90-4.39$ & \\
\hline Pathological TNM & & & & & & & $<0.001^{\mathrm{c}}$ & & & $<0.001$ \\
\hline Stage I & 44 & 12 & 27.3 & 71.9 & 1 & & & 1 & & \\
\hline Stage II & 15 & 9 & 60.0 & 40.0 & 2.81 & $1.18-6.69$ & & 3.51 & $1.35-9.07$ & \\
\hline Stage III & 23 & 16 & 69.7 & 30.4 & 4.44 & $2.08-9.46$ & & 6.54 & $2.86-14.93$ & \\
\hline Histological type & & & & & & & 0.998 & & & 0.857 \\
\hline Nonsquamous & 54 & 25 & 46.3 & 52.9 & 1 & - & & 1 & & \\
\hline Squamous & 28 & 12 & 42.9 & 56.9 & 0.97 & $0.49-1.93$ & & 0.92 & $0.37-2.31$ & \\
\hline ERCC1 & & & & & & & 0.126 & & & 0.059 \\
\hline$\leq 140$ & 33 & 12 & 26.4 & 61.4 & 1 & & & 1 & & \\
\hline$>140$ & 49 & 25 & 51.0 & 47.5 & 1.70 & $0.85-3.39$ & & 2.08 & $0.97-4.44$ & \\
\hline $\mathrm{BRCAl}^{\mathrm{a}}$ & & & & & & & 0.308 & & & 0.750 \\
\hline Negative & 36 & 14 & 40.9 & 60.8 & 1 & & & 1 & & \\
\hline Positive & 45 & 22 & 60.0 & 46.7 & 1.42 & $0.72-2.77$ & & 1.14 & $0.51-2.54$ & \\
\hline $\mathrm{TS}^{\mathrm{a}}$ & & & & & & & 0.242 & & & 0.023 \\
\hline Negative & 66 & 27 & 40.9 & 58.8 & 1 & & & 1 & & \\
\hline Positive & 15 & 9 & 60.0 & 40.0 & 1.56 & $0.74-3.32$ & & 2.93 & $1.16-7.42$ & \\
\hline $\mathrm{p} 53 \mathrm{R} 2^{\mathrm{a}}$ & & & & & & & 0.297 & & & 0.699 \\
\hline Negative & 57 & 27 & 47.4 & 52.1 & 1 & & & 1 & & \\
\hline Positive & 24 & 9 & 37.5 & 61.9 & 0.67 & $0.32-1.43$ & & 0.70 & $0.27-1.83$ & \\
\hline TUBB3 (median $H$-score) & & & & & & & 0.152 & & & 0.354 \\
\hline$\leq 60$ & 42 & 22 & 52.4 & 46.8 & 1 & & & 1 & & \\
\hline$>60$ & 40 & 15 & 37.5 & 62.3 & 0.62 & $0.32-1.19$ & & 0.68 & $0.30-1.55$ & \\
\hline $\mathrm{RRM1}^{\mathrm{a}}$ (median $H$-score) & & & & & & & 0.832 & & & 0.624 \\
\hline$\leq 120$ & 43 & 19 & 44.2 & 54.7 & 1 & & & 1 & & \\
\hline$>120$ & 38 & 17 & 44.7 & 55.3 & 1.07 & $0.56-2.07$ & & 0.82 & $0.36-1.84$ & \\
\hline RRM2 (median $H$-score) & & & & & & & 0.069 & & & 0.031 \\
\hline$\leq 140^{\mathrm{a}}$ & 42 & 16 & 35.7 & 61.9 & 1 & & & 1 & & \\
\hline$>140$ & 39 & 21 & 53.8 & 45.9 & 1.84 & $0.95-3.56$ & & 2.26 & $1.08-4.74$ & \\
\hline
\end{tabular}

${ }^{*} \mathrm{SP}=$ cumulative probability of surviving, ${ }^{\mathrm{a}}$ expression level missing for 1 subject, ${ }^{\mathrm{b}}$ log-rank (Mantel-Cox) test, ${ }^{\mathrm{c}}$ test for trend, ${ }^{\mathrm{d}}$ Cox regression analysis performed on 81 subjects with complete data: $\mathrm{HR}$ and $95 \% \mathrm{CI}$ estimated from the final regression model for covariates retained in the model and from the full model for variables removed, and ${ }^{\mathrm{e}}$ likelihood ratio test $p$ value.

correlation between protein and mRNA expression levels (Table 4) showed significant correlations for RRM1 ( $r=0.29$, $p<0.01)$ and TS $(r=0.47, p<0.05)$ and for TS and TUBB3 $(r=-0.27, p<0.05)$. Recent data consistently suggest that TUBB3 and TS expression were significantly correlated to poor outcomes in NSCLC patients; therefore, their expression could correlate to aggressive tumour behavior and increased proliferative activity $[34,35]$. However, the underlying mechanism relating TUBB3 and TS expression to poor prognosis is unknown and needs to be elucidated by future studies.

When patients were classified into groups based on low and high levels of biomarkers mRNA expression (Table 5), no statistically significant association with OS was detected. $\mathrm{K}-\mathrm{M}$ plots were similar to those obtained for protein levels 
TABLE 4: Correlation between protein and mRNA expression levels.

\begin{tabular}{|c|c|c|c|c|c|c|c|}
\hline Gene & Correlation $^{\mathrm{a}}$ & BRCA1 & ERCC1 & TS & RRM1 & RRM2 & TUBB3 \\
\hline \multirow{2}{*}{ BRCA1 } & $r$ & -0.040 & 0.188 & -0.060 & -0.009 & -0.083 & -0.032 \\
\hline & Number & 80 & 80 & 79 & 79 & 80 & 80 \\
\hline \multirow{2}{*}{ ERCC1 } & $r$ & & 0.152 & -0.040 & 0.078 & 0.092 & -0.080 \\
\hline & Number & & 82 & 81 & 81 & 82 & 82 \\
\hline \multirow{2}{*}{ TS } & $r$ & & & $0.467^{* *}$ & 0.137 & 0.046 & $-0.270^{*}$ \\
\hline & Number & & & 77 & 77 & 78 & 78 \\
\hline \multirow{2}{*}{ RRM1 } & $r$ & & & & $0.286^{*}$ & 0.094 & -0.034 \\
\hline & Number & & & & 71 & 71 & 71 \\
\hline \multirow{2}{*}{ RRM2 } & $r$ & & & & & 0.063 & -0.111 \\
\hline & Number & & & & & 75 & 75 \\
\hline \multirow{2}{*}{ TUBB3 } & $r$ & & & & & & -0.114 \\
\hline & Number & & & & & & 80 \\
\hline
\end{tabular}

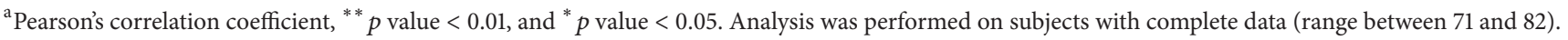

except for TUBB3 for which the trend was inverted indicating a longer OS among patients with lower mRNA expression levels (Figures 3-4). Cox multiple regression limited to 64 subjects with complete data (Table 5) identified only pathological TNM as a significant predictor of OS with worse survival associated to stages II ( $\mathrm{HR}=3.49,95 \% \mathrm{CI}=1.30$ 9.40) and III ( $\mathrm{HR}=4.39,95 \% \mathrm{CI}=1.41-10.68)$ compared to stage I.

3.3. Biomarkers' mRNA Expression in the DCC Microarray Dataset. One hundred and seventy-four out of 330 patients were male $(52.7 \%)$ and $156(47.3 \%)$ were female. The median age at diagnosis was 65 years (range of 33-87). All of the patients had adenocarcinoma. Twenty-five (7.6\%) patients were smokers, 182 (55.2\%) former smokers, and 34 (10.3\%) never-smokers. Smoking was missing for 89 (26.9\%) subjects. Former and current smokers were grouped together in the statistical analysis (Table 6). At 5-year follow-up, a total of $121(36.7 \%)$ deaths were observed. When patients were categorised into groups based on mRNA expression levels of each biomarker (i.e., negative, positive), three genes were found to be significantly associated with OS in univariate analyses (Table 6): BRCA1 (HR $=1.64,95 \% \mathrm{CI}=1.12-2.39$ ), TS $(\mathrm{HR}=1.78,95 \% \mathrm{CI}=1.24-2.56)$, and $\mathrm{RRM} 2(\mathrm{HR}=1.69,95 \%$ $\mathrm{CI}=1.17-2.44)$. The K-M survival curves for these genes are shown in Figure 5. Pathological TNM was a strong predictor of OS ( $\mathrm{HR}=3.19,95 \% \mathrm{CI}=2.18-4.66$ and $\mathrm{HR}=6.45,95 \% \mathrm{CI}$ $=3.43-12.15$ for stages II and III versus stage I, resp.) together with age at diagnosis $(\mathrm{HR}=1.03,95 \% \mathrm{CI}=1.01-1.04$, and age $=$ continuous $)$ and gender $(\mathrm{HR}=0.68,95 \% \mathrm{CI}=0.47-$ 0.98 , females versus males). Cox multiple regression analyses (Table 6) identified age at diagnosis, pathological TNM, and TS (HR $=1.57,95 \%$ CI: $1.08-2.28)$ as variables significantly associated with OS.

\section{Discussion}

We investigated the effect of the expression of seven biomarkers (ERCC1, BRAC1, RRM1, RRM2, P53R2, TUBB3, and TS) on survival in stages I-III NSCLC patients treated with surgery alone. The majority of these markers have already been widely investigated for their predictive role with the aim of customising postoperative adjuvant chemotherapy [36-38] or first line treatment [39-43]. Conversely, many prognostic molecular markers have been described for patients with NSCLC, but none are currently being used to determine the course of treatment [44-50].

Our study is the first that considers all of these markers together, using two different research methods (IHC and qRT-PCR), with the aim of testing their influence on survival and identifying patients with a higher risk of relapse.

TNM stage, widely used in standard practice to select chemotherapy drugs in the treatment of NSCLC, has been confirmed as the main prognostic factor. The need to identify new molecular markers of recurrence for determining clinical outcome and improve survival in patients with early-stage NSCLC has clearly emerged during the recent years. Our study has shown that the protein expression of RRM2 is significantly associated with OS in surgically resected NSCLC patients. In particular, in agreement with recent reports [14, 51], patients with underexpressed RRM2 tumours survived longer after radical surgery than those with overexpressed RRM2 tumours. Thus, loss of DNA repair function may be an advantage for NSCLC patients following tumour resection. Notably, RRM2 was a good prognostic indicator of OS in univariate analyses ( $\mathrm{HR}=1.84,95 \% \mathrm{CI}=0.95-3.56)$ as well as in multivariate Cox regression analysis ( $\mathrm{HR}=2.26,95 \%$ $\mathrm{CI}=1.08-3.56$ ) when the significant effects of pathological TNM, TS, and ERCC1 on OS were taken into account. This finding may reflect the crucial role of RRM2 in supplying deoxyribonucleotides (dNTPs) during DNA synthesis and repair and is in agreement with the observation that a high level of RRM2 expression correlates with cellular invasiveness $[14,15]$, tumour angiogenesis [52], and metastasis [53]. Therefore, patients with tumour cells overexpressing RRM2 may more easily progress, thus supporting our finding that RRM2 expression levels may be a valuable indicator of prognosis.

We also observed that TS protein expression was an unfavourable prognostic factors in multivariate analysis with a trend towards poor postoperative survival among patients 

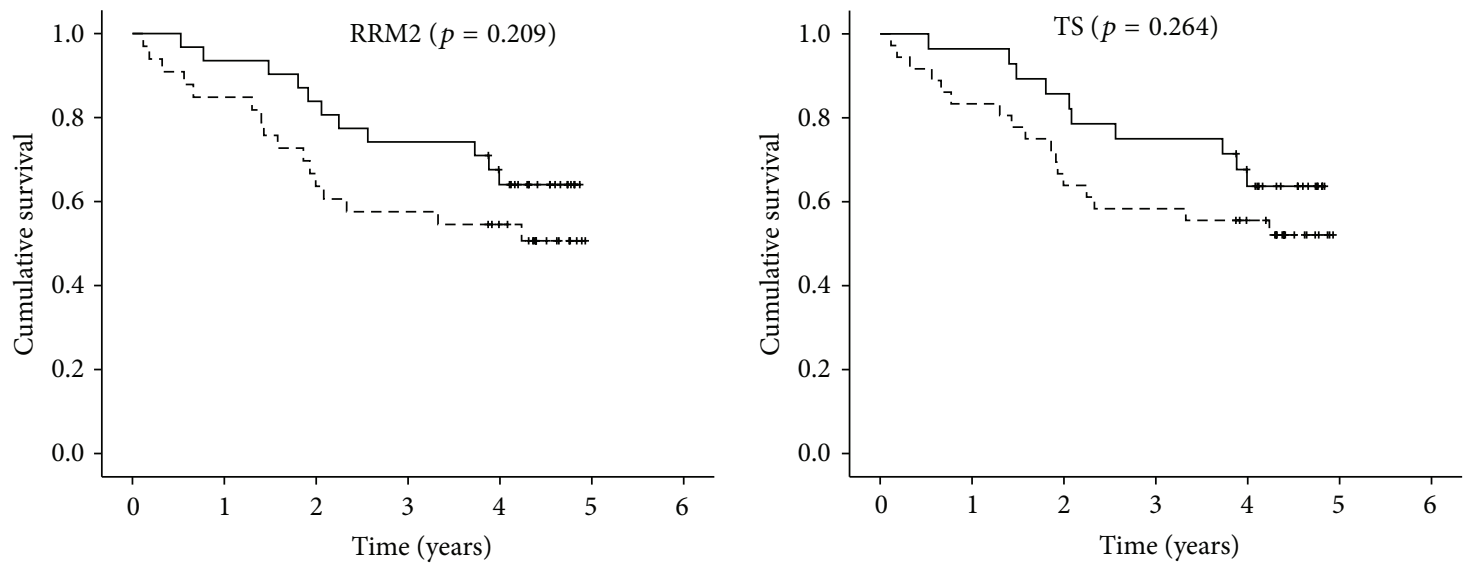

$\neg<0.275$ (median mRNA expression level)

_ $\_0.275$ (median mRNA expression level)

$+<0.275$-censored

$+\geq 0.275$-censored

(a)

$\neg<0.179$ (median mRNA expression level) - ? $\tau^{-} \geq 0.179$ (median mRNA expression level)

$+<0.179$-censored

$+\geq 0.179$-censored

(b)
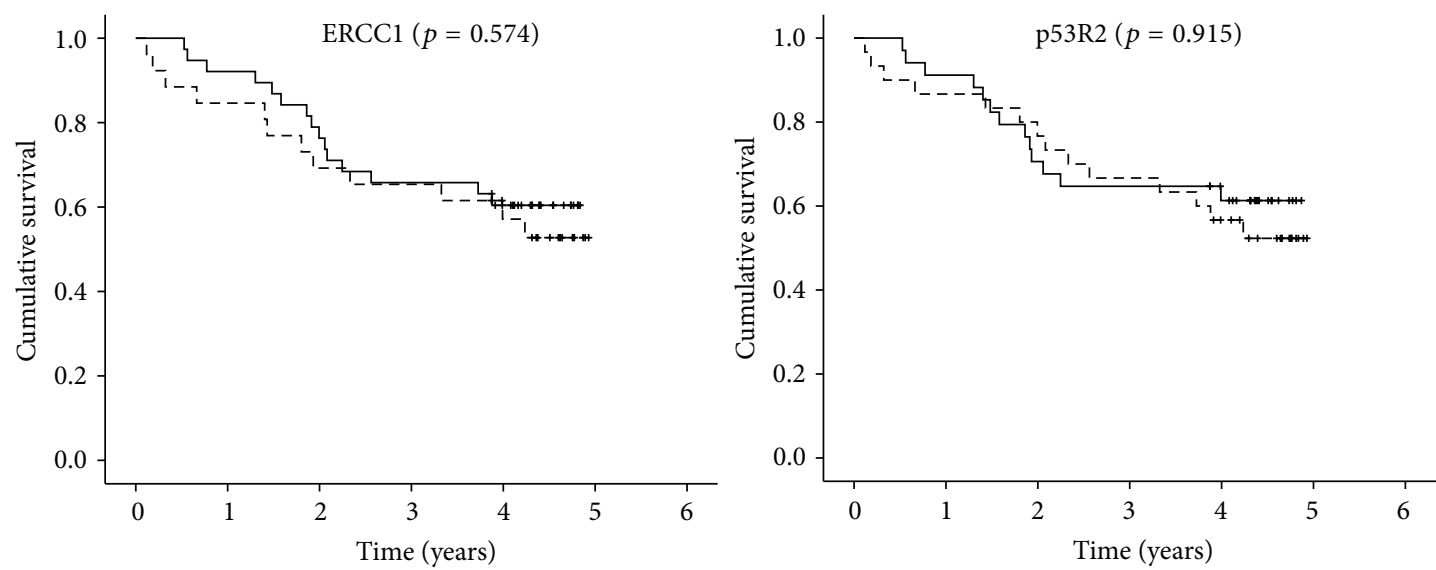

$\neg<0.419$ (median mRNA expression level)

- $-\tau, \geq 0.419$ (median mRNA expression level)

$+<0.419$-censored

$+\geq 0.419$-censored

(c)

$$
\begin{aligned}
& \square<0.054 \text { (median mRNA expression level) } \\
&-\neg \geq 0.054 \text { (median mRNA expression level) } \\
&+\quad<0.054 \text {-censored } \\
&+\quad \geq 0.054 \text {-censored }
\end{aligned}
$$

(d)

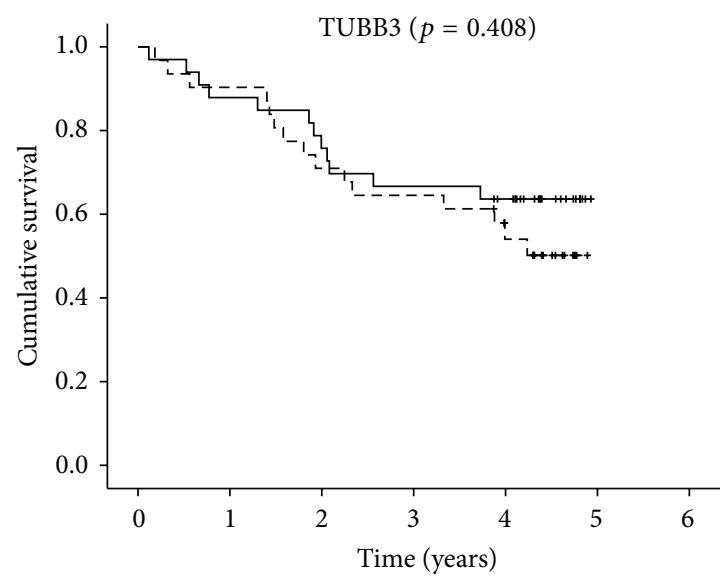

$\neg<0.453$ (median mRNA expression level) $-\neg \geq 0.453$ (median mRNA expression level)

$+<0.453$-censored

$+\geq 0.453$-censored

(e)

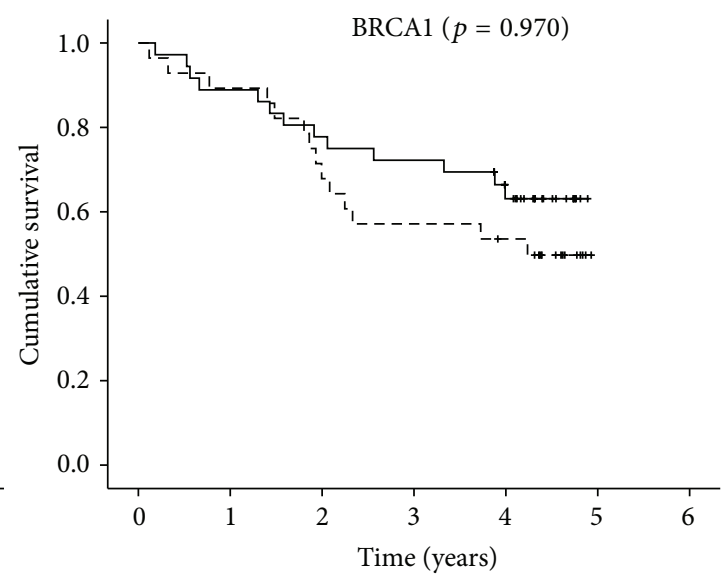

$\neg<0.635$ (median mRNA expression level) _ $-? \geq 0.635$ (median mRNA expression level)

$+<0.635$-censored

$+\geq 0.635$-censored

(f)

Figure 4: Continued. 


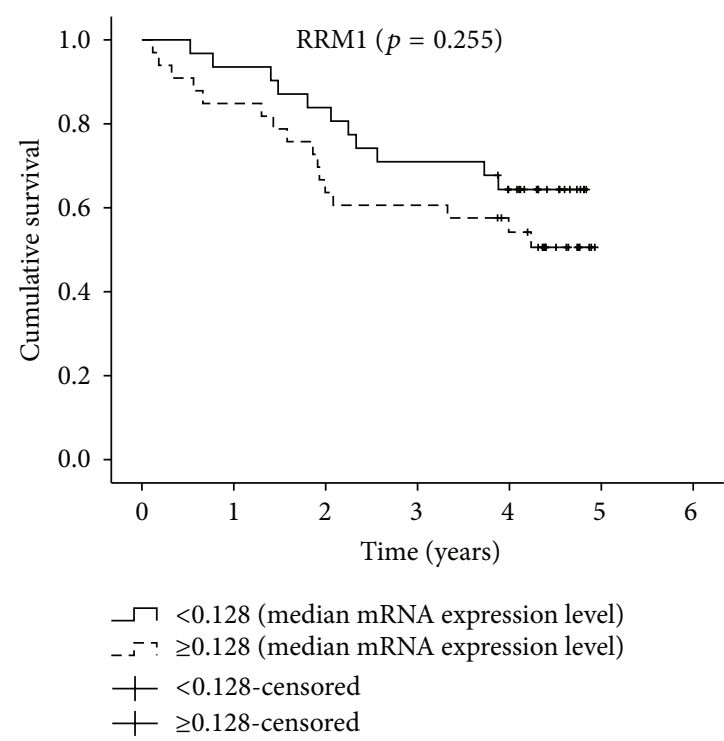

(g)

FIGURE 4: Kaplan-Meier estimates of overall survival according to the mRNA expression levels of (a) RRM2, (b) TS, (c) ERCC1, (d) p53R2, (e) TUBB3, (f) BRCA1, and (g) RRM1 in the overall population.

with tumours overexpressing TS. This result is in agreement with its key role in methylation of deoxyuridine monophosphate (dUMP) to deoxythymidine monophosphate (dTMP), required for DNA synthesis and repair, and with the evidence that TS expression is significantly correlated with increased proliferative activity and aggressive tumour behaviour [54, 55]. Thus, it is realistic to assume that TS might play an important role in regulating the malignant potential in many types of cancer not only in lung cancer. No significant correlation between intratumoural TS protein and gene expression levels and clinicopathologic characteristics was observed. These findings obtained for TS were in agreement with previously reported evidence $[22,35,56,57]$, while discordant results were found for ERCC1. The relevance of ERCC1 expression as prognostic marker has been reported in some studies $[6,58]$ but the conflicting information regarding the pure prognostic role of ERCC1 expression remains and is also supported by our study. Previous studies [58-61] have shown that high ERCC1 levels are associated with longer survival. Conversely, our study showed that there was a tendency towards better prognosis in ERCCl-negative cases, although the difference was not statistically significant. Recent articles $[62,63]$ support this result showing that ERCC1 expression does not affect survival in patient who did not previously receive adjuvant chemotherapy. An additional study [9] showed that a low ERCC1 expression is associated with a significantly better prognosis in stage I NSCLC. The results of our study might be affected by our study population because the majority of our patients were stage I and did not receive any adjuvant chemotherapy. Furthermore, recent studies [64, 65] have suggested that all these conflicting results might depend on the antibody used for the detection of ERCC1. Since none of the ERCC1 antibodies usually used distinguish between functional and nonfunctional isoforms, it might be difficult to validate the correlation between the level of ERCC1 expression and OS on the basis of IHC detection; in effect, the expression of nonfunctional ERCC1 isoforms may lead to false ERCC1-positive cases and biased results.

Although in our study p53R2 did not have a significant effect on OS, it was significantly associated with histotype. There were more p53R2-positive cases in nonsquamous than in squamous NSCLC and this is concordant with a previous study [12] and with the evidence that patients with adenocarcinoma have a worse prognosis than patients with squamous cell carcinoma. We hypothesized its possible role as a marker of more aggressive tumoural phenotype since it plays an important role in the DNA repair pathway and its expression could increase following DNA damage or accumulation of several genetic changes [11]. In this sense, p53R2 may be useful for detecting aggressive tumours with high metastatic potential and a poor prognosis.

Rosell et al. [9] showed that BRCA1 mRNA expression, implicated in transcription-coupled nucleotide excision repair (TC-NER) pathway, was the only independent prognostic variable in chemotherapy-naïve patients with earlystage, resected NSCLC and demonstrated that RRM1 mRNA expression did not show a statistically significant impact on OS. The author reported that prolonged survival was observed in BRCA1- and RRM1-negative tumours but not among patients with BRCA1- and RRM1-positive tumours. According to this study, our findings, using IHC evaluation, have shown that higher expression of BRCA1 and RRM1 correlates with poorer survival in early NSCLC even if the difference between the survival curves was not statistically significant.

Moreover, a previous study has shown that class TUBB3 has a negative prognostic role in patients with curatively resected NSCLC who did not receive adjuvant chemotherapy [66]. Our study did not show a prognostic role of TUBB3 on OS in the same group of NSCLC patients. Moreover, no 

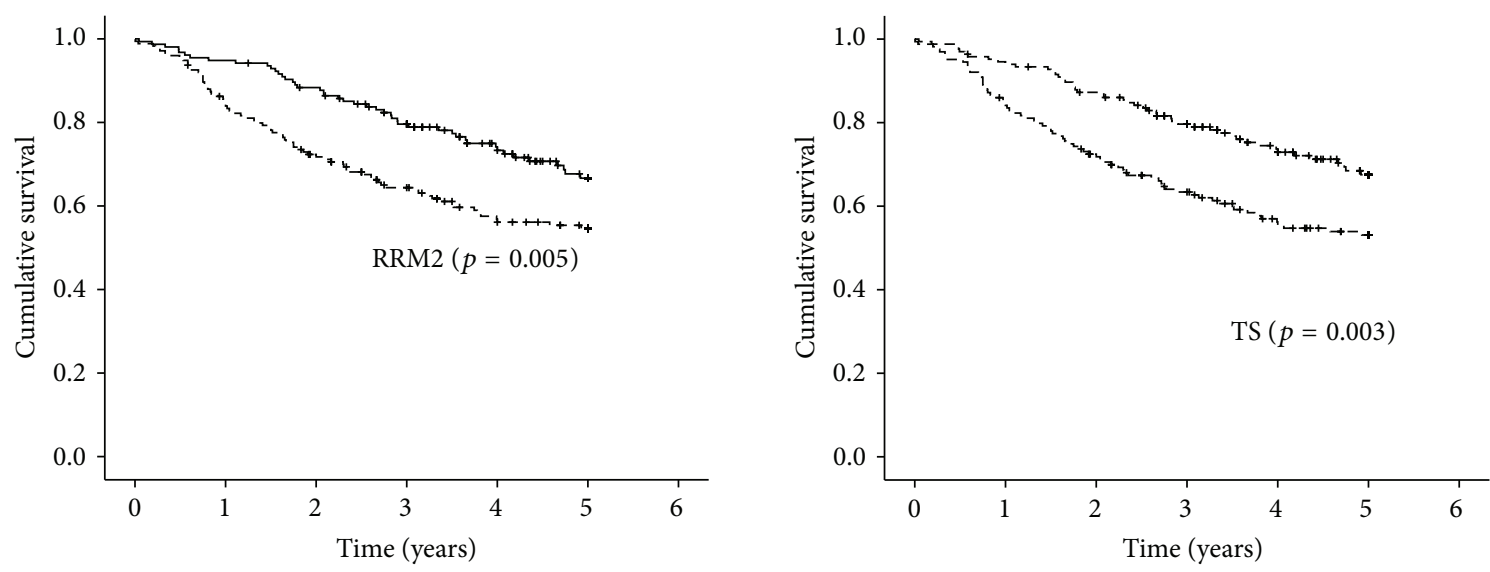

$\neg \leq 0.213$ (median mRNA expression level) $-\tau ?>0.213$ (median mRNA expression level) $+\leq 0.213$ (median mRNA expression level)-censored $+>0.213$ (median mRNA expression level)-censored

(a)

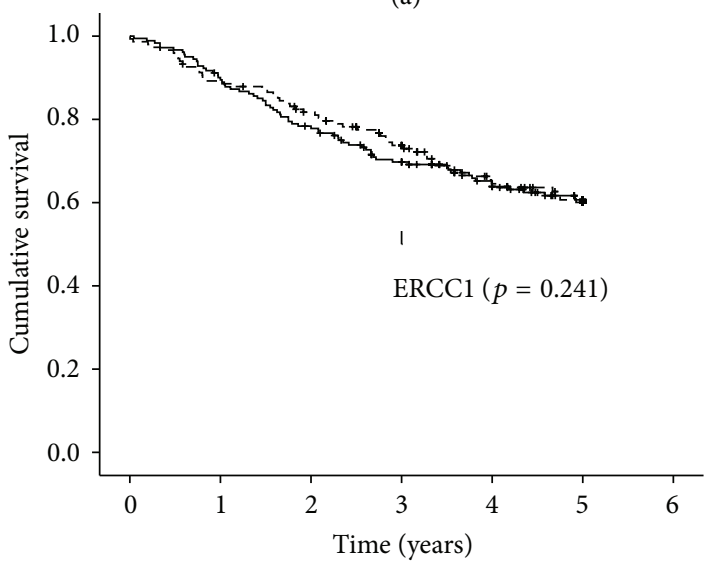

$\neg \leq-0.045$ (median mRNA expression level)

$-\neg ?>-0.045$ (median mRNA expression level)

$+\leq-0.045$ (median mRNA expression level)-censored $+>-0.045$ (median mRNA expression level)-censored

(c)

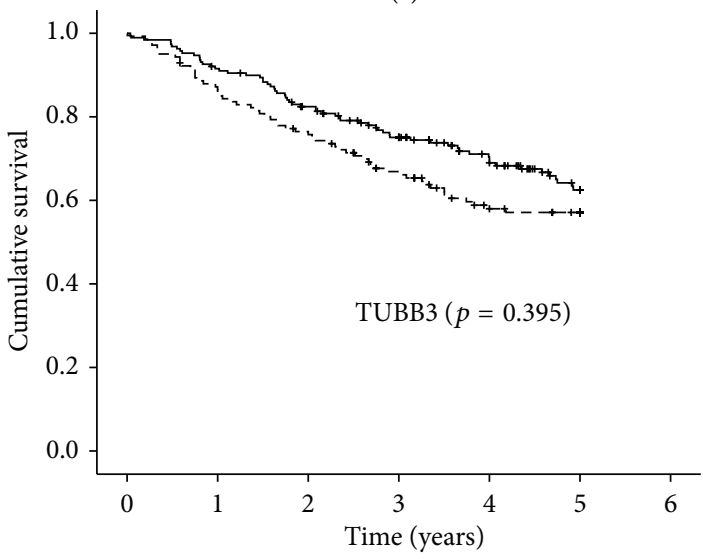

$\neg \leq-0.116$ (median mRNA expression level)

$-\neg>0.116$ (median mRNA expression level)

$+\leq-0.116$ (median mRNA expression level)-censored

$+>-0.116$ (median mRNA expression level)-censored

(e) $-\tau \leq-0.018$ (median mRNA expression level)

$-\tau ?>-0.018$ (median mRNA expression level)

$+\leq-0.018$ (median mRNA expression level)-censored

$+>-0.116$ (median mRNA expression level)-censored

(b)

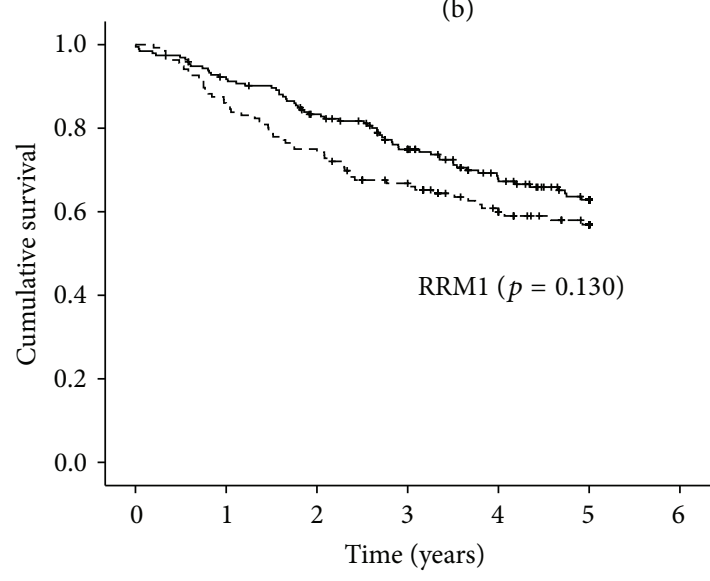

$\neg \leq-0.130$ (median mRNA expression level)

_ $5>-0.130$ (median mRNA expression level)

$+\leq-0.130$ (median mRNA expression level)-censored

$+>-0.130$ (median mRNA expression level)-censored

(d)

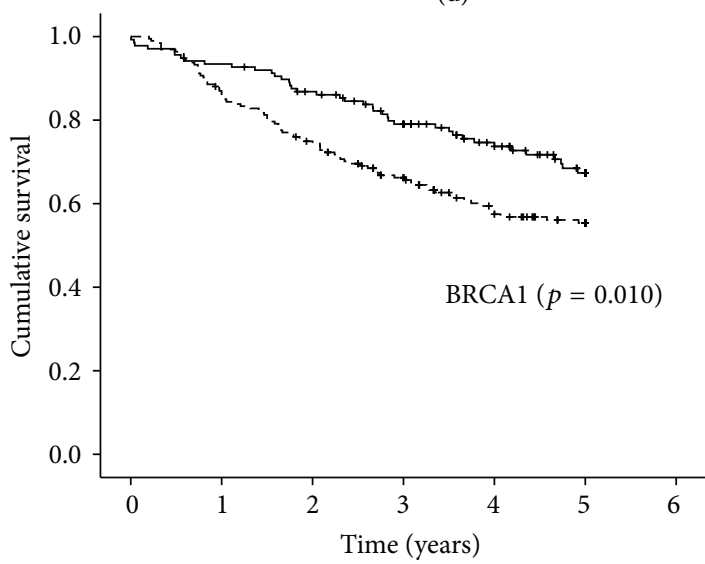

$\neg \leq 0.048$ (median mRNA expression level)

$-\tau ?>0.048$ (median mRNA expression level)

$+\leq 0.048$ (median mRNA expression level)-censored

$+>0.048$ (median mRNA expression level)-censored

(f)

FIgURE 5: Kaplan-Meier estimates of overall survival according to gene expression levels of (a) RRM2, (b) TS, (c) ERCC1, (d) RRM1, (e) TUBB3, and (f) BRCA1 in Shedden 2008 [5] microarray dataset; $N=330$ (adjuvant naïve patient only). Patients were categorised according to mRNA expression levels of each gene. 
TABle 5: Patients characteristics, clinicopathological features, and RT-PCR analysis: association with OS. Results from Kaplan-Meier univariate and Cox multiple regression analyses performed on the subset of patients with complete data $(N=64)$.

\begin{tabular}{|c|c|c|c|c|c|c|c|c|c|c|}
\hline \multirow{3}{*}{ Covariates } & \multirow{3}{*}{$N$} & \multicolumn{3}{|c|}{ 5-year survival } & \multicolumn{3}{|c|}{ Kaplan-Meier } & \multicolumn{3}{|c|}{ Cox regression } \\
\hline & & \multicolumn{2}{|c|}{ Deaths } & \multirow{2}{*}{$\begin{array}{c}\mathrm{SP}^{*} \\
\%\end{array}$} & \multirow[b]{2}{*}{ HR } & \multirow[b]{2}{*}{$95 \% \mathrm{CI}$} & \multirow[b]{2}{*}{$p$ value $^{\mathrm{a}}$} & \multirow[b]{2}{*}{$\mathrm{HR}^{\mathrm{c}}$} & \multirow[b]{2}{*}{$95 \% \mathrm{CI}$} & \multirow[b]{2}{*}{$p$ value $^{\mathrm{d}}$} \\
\hline & & $n$ & $\%$ & & & & & & & \\
\hline Gender & & & & & & & 0.872 & & & 0.826 \\
\hline Female & 15 & 6 & 60.0 & 59.3 & 1 & & & 1 & & \\
\hline Male & 49 & 21 & 43.9 & 56.4 & 1.07 & $0.43-2.67$ & & 0.68 & $0.26-1.78$ & \\
\hline Age at diagnosis & & & & & & & 0.922 & & & 0.678 \\
\hline$\leq 70$ years & 38 & 16 & 42.10 & 57.9 & 1 & & & 1 & & \\
\hline$>70$ years & 26 & 11 & 42.3 & 53.6 & 0.96 & $0.45-2.08$ & & 0.77 & $0.27-2.19$ & \\
\hline Smoking habit & & & & & & & 0.125 & & & 0.174 \\
\hline Ex/never-smoker & 23 & 7 & 30.4 & 69.0 & 1 & & & 1 & & \\
\hline Current smoker & 41 & 21 & 50.0 & 49.3 & 1.97 & $0.83-4.66$ & & 1.81 & $0.76-4.30$ & \\
\hline Pathological TNM & & & & & & & $<0.000^{\mathrm{b}}$ & & & 0.001 \\
\hline Stage I & 37 & 9 & 24.3 & 74.5 & 1 & & & 1 & & \\
\hline Stage II & 11 & 7 & 65.6 & 36.4 & 3.49 & $1.30-9.34$ & & 3.49 & $1.30-9.40$ & \\
\hline Stage III & 16 & 11 & 78.7 & 31.3 & 4.39 & $1.81-10.7$ & & 4.39 & $1.41-10.68$ & \\
\hline Histological type & & & & & & & 0.519 & & & 0.777 \\
\hline Nonsquamous & 39 & 18 & 46.2 & 52.5 & 1 & & & 1 & & \\
\hline Squamous & 25 & 9 & 46.0 & 63.7 & 0.77 & $0.35-1.71$ & & 0.79 & $0.29-2.11$ & \\
\hline ERCC1 (median mRNA expression level) & & & & & & & 0.574 & & & 0.619 \\
\hline$<0.419$ & 38 & 15 & 39.5 & 60.4 & 1 & & & 1 & & \\
\hline$\geq 0.419$ & 26 & 12 & 47.2 & 52.7 & 1.24 & $0.58-2.66$ & & 1.14 & $0.38-3.44$ & \\
\hline $\mathrm{BRCAl}^{\mathrm{a}}$ (median mRNA expression level) & & & & & & & 0.970 & & & 0.854 \\
\hline$<0.071$ & 36 & 15 & 41.7 & 57.8 & 1 & & & 1 & & \\
\hline$\geq 0.071$ & 28 & 12 & 42.9 & 56.7 & 1.02 & $0.47-2.17$ & & 0.97 & $0.37-2.55$ & \\
\hline TS $^{\mathrm{a}}$ (median mRNA expression level) & & & & & & & 0.264 & & & 0.554 \\
\hline$<0.179$ & 28 & 10 & 35.7 & 63.7 & 1 & & & 1 & & \\
\hline$\geq 0.179$ & 36 & 17 & 47.2 & 52.1 & 1.56 & $0.71-3.41$ & & 1.21 & $0.48-3.08$ & \\
\hline p53R2 (median mRNA expression level) & & & & & & & 0.915 & & & 0.807 \\
\hline$<0.054$ & 34 & 14 & 42.2 & 58.4 & 1 & & & 1 & & \\
\hline$<0.054$ & 30 & 13 & 42.7 & 55.7 & 1.04 & $0.49-2.28$ & & 1.07 & $0.39-2.93$ & \\
\hline TUBB3 (median mRNA expression level) & & & & & & & 0.408 & & & 0.355 \\
\hline$<0.453$ & 33 & 12 & 46.4 & 63.6 & 1 & & & 1 & & \\
\hline$\geq 0.453$ & 31 & 15 & 48.4 & 50.2 & 1.38 & $0.65-2.95$ & & 1.46 & $0.67-3.18$ & \\
\hline RRM1 & & & & & & & 0.255 & & & 0.293 \\
\hline$\leq 0.128$ & 31 & 11 & 45.5 & 64.4 & 1 & & & 1 & & \\
\hline$>0.128$ & 33 & 16 & 49.50 & 50.6 & 1.56 & $0.73-3.37$ & & 1.63 & $0.75-3.54$ & \\
\hline RRM2 & & & & & & & 0.209 & & & 0.228 \\
\hline$<0.275$ & 31 & 11 & 45.5 & 64.0 & 1 & & & 1 & & \\
\hline$\geq 0.275$ & 33 & 16 & 49.5 & 50.1 & 1.64 & $0.76-3.53$ & & 1.2 & $0.42-3.46$ & \\
\hline
\end{tabular}

${ }^{*} \mathrm{SP}=$ cumulative probability of surviving, ${ }^{\mathrm{a}} \log$-rank (Mantel-Cox) test, ${ }^{\mathrm{b}}$ test for trend, ${ }^{\mathrm{c}}$ Cox regression analysis performed on 64 subjects with complete data: HR and 95\% CI estimated from the final regression model for covariates retained in the model and from the full model for variables removed, and ${ }^{\mathrm{d}}$ likelihood ratio test $p$ value.

significant correlations between BRCA1, RRM1, and TUBB3 expression levels and clinicopathological characteristics were found. Even though the sample size of the present study is limited, and thus the study itself is underpowered to detect significant differences between biomarkers expression and OS, our results suggest an interesting trend in survival curves not only for RRM2 but also for most of the biomarkers specifically for ERCC1, but also for BRCA1, p53R2, and TUBB3.

A comparison of $\mathrm{K}-\mathrm{M}$ survival curves obtained using IHC and qRT-PCR methodologies showed that there was the same trend for all the biomarkers except for TUBB3 the tendency of which was inverted showing that patients with lower TUBB3-mRNA expression levels had a better OS. 
TABLE 6: Results from the DCC NSCLC microarray subset analyses.

\begin{tabular}{|c|c|c|c|c|c|c|c|c|c|c|}
\hline \multirow{3}{*}{ Covariates } & \multirow{3}{*}{$N$} & \multicolumn{3}{|c|}{ 5-year survival } & \multicolumn{3}{|c|}{ Kaplan-Meier } & \multicolumn{3}{|c|}{ Cox regression $^{c}$} \\
\hline & & \multicolumn{2}{|c|}{ Deaths } & \multirow{2}{*}{$\begin{array}{c}\mathrm{SP}^{*} \\
\%\end{array}$} & \multirow[b]{2}{*}{ HR } & \multirow[b]{2}{*}{$95 \% \mathrm{CI}$} & \multirow[b]{2}{*}{$p$ value $^{\mathrm{a}}$} & \multirow[b]{2}{*}{$\mathrm{HR}^{\mathrm{c}}$} & \multirow[b]{2}{*}{$95 \%$ CI } & \multirow[b]{2}{*}{$p$ value $^{\mathrm{d}}$} \\
\hline & & $n$ & $\%$ & & & & & & & \\
\hline Gender & & & & & & & 0.036 & & & 0.199 \\
\hline Males & 174 & 74 & 52.7 & 55.1 & 1 & & & 1 & & \\
\hline Females & 156 & 47 & 47.3 & 66.8 & 0.68 & $0.47-0.98$ & & 1.25 & $0.87-1.80$ & \\
\hline Age at diagnosis & 330 & 121 & 36.7 & 0.43 & 1.03 & $1.01-1.04$ & 0.008 & 1.03 & $1.01-1.05$ & 0.003 \\
\hline Smoking habits & & & & & & & 0.224 & & & 0.747 \\
\hline Ex/never-smoker & 216 & 71 & 65.5 & 63.9 & 1 & & & 1 & & \\
\hline Current smoker & 25 & 10 & 7.6 & 56.2 & 1.32 & $0.68-2.57$ & & 0.86 & $0.56-1.33$ & \\
\hline Unknown & 89 & 40 & 26.9 & 53.6 & 1.39 & $0.94-2.05$ & & 1.09 & $0.53-2.26$ & \\
\hline Pathological TNM & & & & & & & $0.000^{\mathrm{b}}$ & & & 0.000 \\
\hline Stage I & 232 & 60 & 25.9 & 71.2 & 1 & & & 1 & & \\
\hline Stage II & 84 & 49 & 58.3 & 39.4 & 3.19 & $2.19-4.66$ & & 3.32 & $2.15-4.62$ & \\
\hline Stage III & 14 & 12 & 85.7 & 0.00 & 6.45 & $3.43-12.15$ & & 5.39 & $2.84-10.23$ & \\
\hline $\begin{array}{l}\text { ERCC1 (median mRNA } \\
\text { expression level) }\end{array}$ & & & & & & & 0.241 & & & 0.525 \\
\hline$\leq-0.045$ & 181 & 68 & 37.6 & 0.60 & 1 & & & 1 & & \\
\hline$>-0.045$ & 149 & 53 & 35.6 & 0.61 & 0.96 & $0.67-1.37$ & & 1.39 & $0.96-2.04$ & \\
\hline $\begin{array}{l}\text { BRCA1 (median mRNA } \\
\text { expression level) }\end{array}$ & & & & & & & 0.010 & & & 0.614 \\
\hline$\leq 0.048$ & 137 & 40 & 29.2 & 0.68 & 1 & & & 1 & & \\
\hline$>0.048$ & 193 & 81 & 46.7 & 0.53 & 1.64 & $1.12-2.39$ & & 0.95 & $0.58-1.56$ & \\
\hline $\begin{array}{l}\text { TS (median mRNA } \\
\text { expression level) }\end{array}$ & & & & & & & 0.003 & & & 0.017 \\
\hline$\leq-0.018$ & 166 & 48 & 38.1 & 0.67 & 1 & & & 1 & & \\
\hline$>-0.018$ & 164 & 73 & 44.5 & 0.59 & 1.78 & $1.24-2.56$ & & 1.57 & $1.08-2.28$ & \\
\hline $\begin{array}{l}\text { TUBB3 (median } \\
\text { mRNA expression } \\
\text { level) }\end{array}$ & & & & & & & 0.395 & & & 0.890 \\
\hline$\leq-0.116$ & 189 & 63 & 33.3 & 0.63 & 1 & & & 1 & & \\
\hline$>-0.116$ & 141 & 58 & 41.1 & 0.57 & 1.17 & $0.82-1.67$ & & 1.21 & $0.82-1.78$ & \\
\hline $\begin{array}{l}\text { RRM1 (median mRNA } \\
\text { expression level) }\end{array}$ & & & & & & & 0.130 & & & 0.419 \\
\hline$\leq-0.130$ & 194 & 65 & 33.5 & 0.63 & 1 & & & 1 & & \\
\hline$>-0.130$ & 136 & 56 & 41.2 & 0.57 & 1.32 & $0.92-1.89$ & & 0.88 & $0.59-1.32$ & \\
\hline $\begin{array}{l}\text { RRM2 (median mRNA } \\
\text { expression level) }\end{array}$ & & & & & & & 0.005 & & & 0.757 \\
\hline$\leq 0.213$ & 155 & 46 & 29.7 & 0.67 & 1 & & & 1 & & \\
\hline$>0.213$ & 175 & 75 & 42.9 & 0.55 & 1.69 & $1.17-2.44$ & & 1.06 & $0.59-1.88$ & \\
\hline
\end{tabular}

${ }^{*} \mathrm{SP}=$ cumulative probability of surviving, ${ }^{\mathrm{a}}$ log-rank (Mantel-Cox) test, ${ }^{\mathrm{b}}$ test for trend, ${ }^{\mathrm{c}} \mathrm{HR}$ and $95 \% \mathrm{CI}$ from the final regression model for covariates retained in the model and from the full model for variables removed, and ${ }^{\mathrm{d}}$ likelihood ratio test $p$ value.

In addition, a significant correlation between protein and transcript was observed for RRM1 and TS $(r=0.29$ and $r=0.47$, resp.) and for TS and TUBB3 $(r=-0.27)$ only. These findings are in agreement with preliminary evidence reported by others [67], which showed that there is not always a correlation between mRNA and protein expression levels. The lack of significant correlation between transcript and protein observed for most of the biomarkers could be explained by several causes. Our study is a retrospective study with an uncontrolled patient selection process that could potentially generate conflicting data. In addition, the use of archived material for the analysis of gene and protein expression has some limitations including the quantity and quality of available tissue and RNA degradation. Moreover, we should also take account of some aspects of PCR. The technique of RT-PCR allows for establishing quantitative mRNA expression profile of cells and tissues for which the sequence of the genes is known. However, the mRNA 
expression patterns are necessary but are by themselves insufficient for the quantitative description of biological systems. These evidences include discoveries of posttranscriptional mechanisms controlling the protein translation rate [68], the half-lives of specific proteins or mRNAs [69], and the intracellular location and molecular association of the protein products of expressed genes [70]. Moreover, due to the tumour heterogeneity, also IHC analysis with the use of TMA is limited, based on the quality and quantity of the tissue, being the small biopsies collected not necessarily representative of the whole extension of malignant disease. For the same reason, the intratumour heterogeneous biomarkers distribution and expression within the tumours may have influenced our results [46]. Altogether, these aspects could explain the reason for the lack of correlation between gene and protein expression levels and between biomarkers mRNA expression and OS observed in our study.

Finally, we decided to compare the results obtained by qRT-PCR with those obtained by the analysis of the largest NSCLC microarray dataset [5] available and used as a reference in many studies that includes high quality clinical and pathological data. A substantial agreement was observed between the K-M survival plots for our patients with the corresponding K-M survival plots for the microarray dataset. We observed a concordance in both the direction and the size of the effect of gene expression on OS for all biomarkers with the exception of ERCC1 indicating that the result obtained for ERCC1 is specific of our set of patients. The NSCLC microarray dataset confirmed RRM2 and TS as markers significantly associated with OS in univariate analysis; multivariate analysis showed TS as an independent marker of OS, supporting its prognostic potential in NSCLC patients.

\section{Conclusion}

In summary, RRM2 and TS protein expressions were identified as unfavourable prognostic markers in curatively resected NSCLC patients. Patients whose tumours are positive for RRM2 and TS have a significantly worse survival with a twofold increased adjusted hazard in patients with NSCLC overexpressing these markers. This information could be useful to select patients that might be treated with adjuvant chemotherapy. The mechanism behind the reduced survival in these patients warrants further research and has yet to be elucidated by in vitro research and by specifically designed, prospective studies that address the prognostic role of RRM2 and TS expression in NSCLC resected patients.

\section{Conflict of Interests}

The authors declare that they have no conflict of interests.

\section{Authors' Contribution}

Francesco Grossi conceived the study, contributed to the interpretation of the data, and wrote the paper. Maria Giovanna Dal Bello contributed to the interpretation of the data, wrote the paper, and was responsible of the preparation process for the submission of the paper. Domenico Franco Merlo performed the preliminary and final IHC and qRT-PCR statistical analysis and participated in the writing of the paper. Ulrich Pfeffer was responsible for the qRT-PCR experiments and interpretation. Vincenzo Fontana contributed to the final IHC and qRT-PCR analysis. Roberto Puzone performed the microarray dataset analysis and participated in the interpretation. Sandra Salvi and Mauro Truini were responsible for the selection of the tissues, tissue preparation, and IHC evaluation and interpretation. Angela Alama, Erika Rijavec, Giulia Barletta, Carlo Genova, and Claudio Sini collected the clinical data, prepared the database, and contributed to interpretation of the data. Giovanni Battista Ratto and Mario Taviani resected all of the tumours from the patients enrolled in the study and collected the clinical data. All of the authors have revised and approved the final version of this paper.

\section{Acknowledgment}

This work has been supported by a grant from Ricerca Finalizzata 2009 (RF-2009-1530324), Ministero della Salute, Italy.

\section{References}

[1] A. Jemal, T. Murray, E. Ward et al., "Cancer statistics, 2005," CA: A Cancer Journal for Clinicians, vol. 55, no. 1, pp. 10-30, 2005.

[2] P. Goldstraw, J. Crowley, K. Chansky et al., "The IASLC Lung Cancer Staging Project: proposals for the revision of the TNM stage groupings in the forthcoming (seventh) edition of the TNM Classification of malignant tumours," Journal of Thoracic Oncology, vol. 2, no. 8, pp. 706-714, 2007.

[3] NCCN Guidelines-Non Small Cell Lung Cancer: Version $2 / 2013$.

[4] M. Tiseo, V. Franciosi, F. Grossi, and A. Ardizzoni, "Adjuvant chemotherapy for non-small cell lung cancer: ready for clinical practice?" European Journal of Cancer, vol. 42, no. 1, pp. 8-16, 2006.

[5] K. Shedden, J. M. G. Taylor, S. A. Enkemann et al., "Gene expression-based survival prediction in lung adenocarcinoma: a multi-site, blinded validation study," Nature Medicine, vol. 14, no. 8, pp. 822-827, 2008.

[6] K. A. Olaussen, A. Dunant, P. Fouret et al., "DNA repair by ERCC1 in non-small-cell lung cancer and cisplatin-based adjuvant chemotherapy," The New England Journal of Medicine, vol. 355, no. 10, pp. 983-991, 2006.

[7] G. Bepler, K. A. Olaussen, A.-L. Vataire et al., "ERCC1 and RRM1 in the international adjuvant lung trial by automated quantitative in situ analysis," American Journal of Pathology, vol. 178, no. 1, pp. 69-78, 2011.

[8] R. D. Kennedy, J. E. Quinn, P. G. Johnston, and D. P. Harkin, "BRCA1: mechanisms of inactivation and implications for management of patients," The Lancet, vol. 360, no. 9338, pp. 1007-1014, 2002.

[9] R. Rosell, M. Skrzypski, E. Jassem et al., "BRCA1: a novel prognostic factor in resected non-small-cell lung cancer," PLoS ONE, vol. 2, no. 11, Article ID el129, 2007. 
[10] J. G. Cory, "Purine and pyrimidine nucleotide metabolism," in Biochemistry with Clinical Correlation, T. Devlin, Ed., pp. 825860, Wiley-Liss, New York, NY, USA, 1997.

[11] H. Tanaka, H. Arakawa, T. Yamaguchi et al., "A ribonucleotide reductase gene involved in a p53-dependent cell-cycle checkpoint for DNA damage," Nature, vol. 404, no. 6773, pp. 42-49, 2000.

[12] H. Uramoto, K. Sugio, T. Oyama, T. Hanagiri, and K. Yasumoto, "p53R2, p53 inducible ribonucleotide reductase gene, correlated with tumor progression of non-small cell lung cancer," Anticancer Research, vol. 26, no. 2, pp. 983-988, 2006.

[13] N.-Y. Hsu, J.-Y. Wu, X. Liu et al., "P53R2 expression as a prognostic biomarker in early stage non-small cell lung cancer," Oncology Letters, vol. 1, no. 4, pp. 609-613, 2010.

[14] N.-Y. Hsu, J.-Y. Wu, X. Liu et al., "Expression status of ribonucleotide reductase small subunits hRRM2/p53R2 as prognostic biomarkers in stage I and II non-small cell lung cancer," Anticancer Research, vol. 31, no. 10, pp. 3475-3481, 2011.

[15] G. Bepler, A. Gautam, L. M. McIntyre et al., "Prognostic significance of molecular genetic aberrations on chromosome segment 11p15.5 in Non-small-cell lung cancer," Journal of Clinical Oncology, vol. 20, no. 5, pp. 1353-1360, 2002.

[16] B.-S. Zhou, P. Tsai, R. Ker et al., "Overexpression of transfected human ribonucleotide reductase M2 subunit in human cancer cells enhances their invasive potential," Clinical \& Experimental Metastasis, vol. 16, no. 1, pp. 43-49, 1998.

[17] M. S. Duxbury and E. E. Whang, "RRM2 induces NF- $\kappa$ Bdependent MMP-9 activation and enhances cellular invasiveness," Biochemical and Biophysical Research Communications, vol. 354, no. 1, pp. 190-196, 2007.

[18] P. Sève and C. Dumontet, "Is class III beta-tubulin a predictive factor in patients receiving tubulin-binding agents?" The Lancet Oncology, vol. 9, no. 2, pp. 168-175, 2008.

[19] K. Azuma, T. Sasada, A. Kawahara et al., "Expression of ERCC1 and class III beta-tubulin in non-small cell lung cancer patients treated with carboplatin and paclitaxel," Lung Cancer, vol. 64, no. 3, pp. 326-333, 2009.

[20] T. Reiman, R. Lai, A. S. Veillard et al., "Cross-validation study of class III beta-tubulin as a predictive marker for benefit from adjuvant chemotherapy in resected non-small-cell lung cancer: analysis of four randomized trials," Annals of Oncology, vol. 23, no. 1, pp. 86-93, 2012.

[21] P. Ceppi, M. Volante, S. Saviozzi et al., "Squamous cell carcinoma of the lung compared with other histotypes shows higher messenger RNA and protein levels for thymidylate synthase," Cancer, vol. 107, no. 7, pp. 1589-1596, 2006.

[22] T. Nakagawa, F. Tanaka, Y. Otake et al., "Prognostic value of thymidylate synthase expression in patients with p-stage I adenocarcinoma of the lung," Lung Cancer, vol. 35, no. 2, pp. 165-170, 2002.

[23] F. Grossi, R. Spizzo, D. Bordo et al., "Prognostic stratification of stage IIIA pN2 non-small cell lung cancer by hierarchical clustering analysis of tissue microarray immunostaining data: an $\alpha$ Adria Thoracic Oncology Multidisciplinary Group study (ATOM 014)," Journal of Thoracic Oncology, vol. 5, no. 9, pp. 1354-1360, 2010.

[24] S. Salvi, V. Fontana, S. Boccardo et al., "Evaluation of CTLA4 expression and relevance as a novel prognostic factor in patients with non-small cell lung cancer," Cancer Immunology, Immunotherapy, vol. 61, no. 9, pp. 1463-1472, 2012.

[25] H. W. Lee, Y.-W. Choi, J. H. Han et al., "Expression of excision repair cross-complementation group 1 protein predicts poor outcome in advanced non-small cell lung cancer patients treated with platinum-based doublet chemotherapy," Lung Cancer, vol. 65, no. 3, pp. 377-382, 2009.

[26] J. J. Lee, C. H. Maeng, S. K. Baek et al., "The immunohistochemical overexpression of ribonucleotide reductase regulatory subunit M1 (RRM1) protein is a predictor of shorter survival to gemcitabine-based chemotherapy in advanced non-small cell lung cancer (NSCLC)," Lung Cancer, vol. 70, no. 2, pp. 205-210, 2010.

[27] R. Chari, K. M. Lonergan, L. A. Pikor et al., "A sequencebased approach to identify reference genes for gene expression analysis," BMC Medical Genomics, vol. 3, article 32, 2010.

[28] M. J. Kwon, E. Oh, S. Lee et al., "Identification of novel reference genes using multiplatform expression data and their validation for quantitative gene expression analysis," PLOS ONE, vol. 4, no. 7, Article ID e6162, 2009.

[29] R. Puzone, G. Savarino, S. Salvi et al., "Glyceraldehyde-3phosphate dehydrogenase gene over expression correlates with poor prognosis in non small cell lung cancer patients," Molecular Cancer, vol. 12, no. 1, article 97, 2013.

[30] Z. Wu and R. A. Irizarry, "Processing of oligonucleotide array data," Nature Biotechnology, vol. 22, no. 6, pp. 656-658, 2004.

[31] C. M. Bryant, D. L. Albertus, S. Kim et al., "Clinically relevant characterization of lung adenocarcinoma subtypes based on cellular pathways: an international validation study," PLOS ONE, vol. 5, no. 7, Article ID e11712, 2010.

[32] IBM Corp, IBM SPSS Statistics for Windows, Version 20, IBM Corp, Armonk, NY, USA, 2010.

[33] R. C. Gentleman, V. J. Carey, D. M. Bates et al., "Bioconductor: open software development for computational biology and bioinformatics," Genome Biology, vol. 5, no. 10, article R80, 2004.

[34] P. Seve, S. Isaac, O. Tredan et al., "Expression of class III $\beta$ tubulin is predictive of patient outcome in patients with nonsmall cell lung cancer receiving vinorelbine-based chemotherapy," Clinical Cancer Research, vol. 11, no. 15, pp. 5481-5486, 2005.

[35] K. Kaira, Y. Ohde, K. Nakagawa et al., "Thymidylate synthase expression is closely associated with outcome in patients with pulmonary adenocarcinoma," Medical Oncology, vol. 29, no. 3, pp. 1663-1672, 2012.

[36] Z. Q. Zou, Y. Y. Du, G. Sui, and S. N. Xu, "Expression of TS, RRM1, ERCC1, TUBB3 and STMN1 genes in tissues of non-small cell lung cancer and its significance in guiding postoperative adjuvant chemotherapy," Asian Pacific Journal of Cancer Prevention, vol. 16, no. 8, pp. 3189-3194, 2015.

[37] Y. W. He, M. L. Zhao, X. Y. Yang, J. Zeng, Q. H. Deng, and J. X. He, "Prognostic value of ERCC1, RRM1, and TS proteins in patients with resected non-small cell lung cancer," Cancer Chemotherapy and Pharmacology, vol. 75, no. 4, pp. 861-867, 2015.

[38] S. Wallerek and J. B. Sørensen, "Biomarkers for efficacy of adjuvant chemotherapy following complete resection in NSCLC stages I-IIIA," European Respiratory Review, vol. 24, no. 136, pp. 340-355, 2015.

[39] Z. Li, Y. Qing, W. Guan et al., "Predictive value of APE1, BRCA1, ERCC1 and TUBB3 expression in patients with advanced nonsmall cell lung cancer (NSCLC) receiving first-line platinumpaclitaxel chemotherapy," Cancer Chemotherapy and Pharmacology, vol. 74, no. 4, pp. 777-786, 2014.

[40] S. H. Lee, K. B. Noh, J. S. Lee et al., "Thymidylate synthase and ERCC1 as predictive markers in patients with pulmonary 
adenocarcinoma treated with pemetrexed and cisplatin," Lung Cancer, vol. 81, no. 1, pp. 102-108, 2013.

[41] K. Domvri, P. Zarogoulidis, K. Darwiche et al., "Molecular targeted drugs and biomarkers in NSCLC, the evolving role of individualized therapy," Journal of Cancer, vol. 4, no. 9, pp. 736754, 2013.

[42] M. Joerger, D. deJong, A. Burylo et al., "Tubuline, BRCA1, ERCC1, Abraxas, RAP80 mRNA expression, p53/p21 immunohistochemistry and clinical outcome in patients with advanced non small-cell lung cancer receiving first-line platinumgemcitabine chemotherapy," Lung Cancer, vol. 74, no. 2, pp. 310317, 2011.

[43] I. Boukovinas, C. Papadaki, P. Mendez et al., "Tumor BRCA1, RRM1 and RRM2 mRNA expression levels and clinical response to first-line gemcitabine plus docetaxel in non-small-cell lung cancer patients," PLoS ONE, vol. 3, no. 11, Article ID e3695, 2008.

[44] S. Tian, C. Wang, and M. A. An, "Test on existence of histology subtype-specific prognostic signatures among early stage lung adenocarcinoma and squamous cell carcinoma patients using a Cox-model based filter," Biology Direct, vol. 10, article 15, 2015.

[45] S. Peters, W. Weder, U. Dafni et al., "Lungscape: resected nonsmall-cell lung cancer outcome by clinical and pathological parameters," Journal of Thoracic Oncology, vol. 9, no. 11, pp. 1675-1684, 2014.

[46] J. N. Jakobsen, E. Santoni-Rugiu, J. Ravn, and J. B. Sørensen, "Intratumour variation of biomarker expression by immunohistochemistry in resectable non-small cell lung cancer," European Journal of Cancer, vol. 49, no. 11, pp. 2494-2503, 2013.

[47] B. Győrffy, P. Surowiak, J. Budczies, and A. Lánczky, “Online survival analysis software to assess the prognostic value of biomarkers using transcriptomic data in non-small-cell lung cancer," PLoS ONE, vol. 8, no. 12, Article ID e82241, 2013.

[48] Y.-W. Wan, D. G. Beer, and N. L. Guo, "Signaling pathway-based identification of extensive prognostic gene signatures for lung adenocarcinoma," Lung Cancer, vol. 76, no. 1, pp. 98-105, 2012.

[49] M. Pesta, V. Kulda, O. Fiala et al., "Prognostic significance of ERCC1, RRM1 and BRCA1 in surgically-treated patients with non-small cell lung cancer," Anticancer Research, vol. 32, no. 11, pp. 5003-5010, 2012.

[50] K. Kaira and N. Yamamoto, "Prognostic and predictive factors in resected non-small-cell lung cancer," Expert Opinion on Medical Diagnostics, vol. 4, no. 5, pp. 373-381, 2010.

[51] V. Mah, M. Alavi, D. C. Márquez-Garbán et al., "Ribonucleotide reductase subunit M2 predicts survival in subgroups of patients with non-small cell lung carcinoma: effects of gender and smoking status," PLoS ONE, vol. 10, no. 5, Article ID e0127600, 2015.

[52] K. Zhang, S. Hu, J. Wu et al., "Overexpression of RRM2 decreases thrombspondin-1 and increases VEGF production in human cancer cells in vitro and in vivo: implication of RRM2 in angiogenesis," Molecular Cancer, vol. 8, article 11, 2009.

[53] B.-S. Zhou, P. Tsai, R. Ker et al., "Overexpression of transfected human ribonucleotide reductase M2 subunit in human cancer cells enhances their invasive potential," Clinical and Experimental Metastasis, vol. 16, no. 1, pp. 43-49, 1998.

[54] P. J. Ferguson, O. Collins, N. M. Dean et al., "Antisense downregulation of thymidylate synthase to suppress growth and enhance cytotoxicity of 5-FUdR, 5-FU and Tomudex in HeLa cells," British Journal of Pharmacology, vol. 127, no. 8, pp. 17771786, 1999.

[55] C. Burdelski, C. Strauss, M. C. Tsourlakis et al., "Overexpression of thymidylate synthase (TYMS) is associated with aggressive tumor features and early PSA recurrence in prostate cancer," Oncotarget, vol. 6, no. 10, pp. 8377-8387, 2015.

[56] H.-Y. Zhao, G.-W. Ma, B.-Y. Zou et al., "Prognostic significance of thymidylate synthase in postoperative non-small cell lung cancer patients," OncoTargets and Therapy, vol. 7, pp. 1301-1310, 2014.

[57] P. V. Danenberg, "Thymidylate synthetase-a target enzyme in cancer chemotherapy," Biochimica et Biophysica Acta, vol. 473, no. 2, pp. 73-92, 1977.

[58] K.-H. Lee, H. S. Min, S.-W. Han et al., "ERCC1 expression by immunohistochemistry and EGFR mutations in resected nonsmall cell lung cancer," Lung Cancer, vol. 60, no. 3, pp. 401-407, 2008.

[59] Z. Zheng, T. Chen, X. Li, E. Haura, A. Sharma, and G. Bepler, "DNA synthesis and repair genes RRM1 and ERCC1 in lung cancer," The New England Journal of Medicine, vol. 356, no. 8, pp. 800-808, 2007.

[60] G. R. Simon, S. Sharma, A. Cantor, P. Smith, and G. Bepler, "ERCC1 expression is a predictor of survival in resected patients with non-small cell lung cancer," Chest, vol. 127, no. 3, pp. 978983, 2005.

[61] E. C. Seyhan, S. Altin, E. Çetinkaya et al., "Prognostic significance of ERCC1 expression in resected non small cell lung carcinoma," Annals of Thoracic and Cardiovascular Surgery, vol. 17, no. 2, pp. 110-117, 2011.

[62] K. Okuda, H. Sasaki, Y. Hikosaka et al., "Excision repair cross complementation group 1 polymorphisms predict overall survival after platinum-based chemotherapy for completely resected non-small-cell lung cancer," Journal of Surgical Research, vol. 168, no. 2, pp. 206-212, 2011.

[63] A. Tantraworasin, S. Saeteng, N. Lertprasertsuke, N. Arayawudhikul, C. Kasemsarn, and J. Patumanond, "The prognostic value of ERCC1 and RRM1 gene expression in completely resected non-small cell lung cancer: tumor recurrence and overall survival," Cancer Management and Research, vol. 5, no. 1, pp. 327-336, 2013.

[64] L. Friboulet, K. A. Olaussen, J.-P. Pignon et al., "ERCC1 isoform expression and DNA repair in non-small-cell lung cancer," The New England Journal of Medicine, vol. 368, no. 12, pp. 1101-1110, 2013.

[65] T. R. Muley, M. Sianidou, M. Thomas et al., "Comparison of two ERCC1 antibodies as prognostic and predictive biomarkers for early non-small cell lung cancer," Anticancer Research, vol. 34, no. 7, pp. 3707-3713, 2014.

[66] Y. Koh, B. Jang, S.-W. Han et al., "Expression of class III $\beta$ tubulin correlates with unfavorable survival outcome in patients with resected non-small cell lung cancer," Journal of Thoracic Oncology, vol. 5, no. 3, pp. 320-325, 2010.

[67] A. Vilmar, J. Garcia-Foncillas, M. Huarriz, E. Santoni-Rugiu, and J. B. Sorensen, "RT-PCR versus immunohistochemistry for correlation and quantification of ERCC1, BRCA1, TUBB3 and RRM1 in NSCLC," Lung Cancer, vol. 75, no. 3, pp. 306-312, 2012.

[68] J. B. Harford and D. R. Morris, Post-Transcriptional Gene Regulation, Wiley-Liss, New York, NY, USA, 1997.

[69] A. Varshavsky, "The N-end rule: functions, mysteries, uses," Proceedings of the National Academy of Sciences of the United States of America, vol. 93, no. 22, pp. 12142-12149, 1996.

[70] S. Urlinger, K. Kuchler, T. H. Meyer, S. Uebel, and R. Tampé, "Intracellular location, complex formation, and function of the transporter associated with antigen processing in yeast," European Journal of Biochemistry, vol. 245, no. 2, pp. 266-272, 1997. 


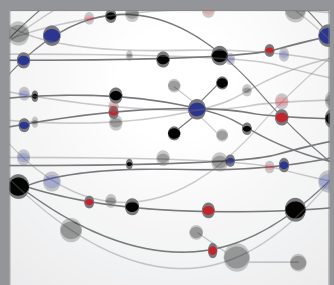

The Scientific World Journal
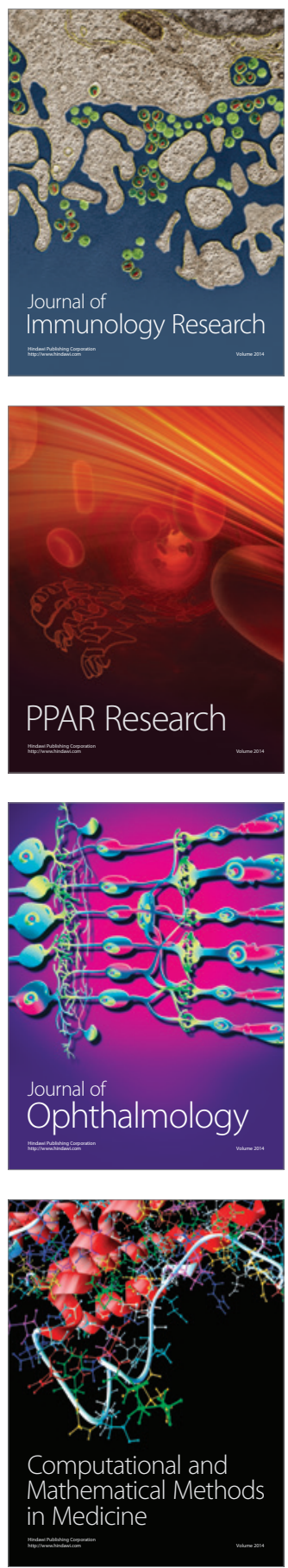

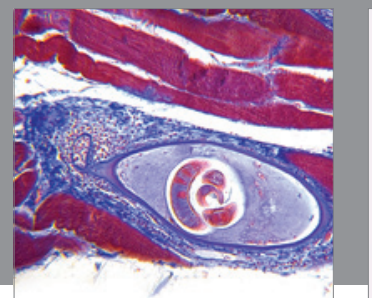

Gastroenterology

Research and Practice
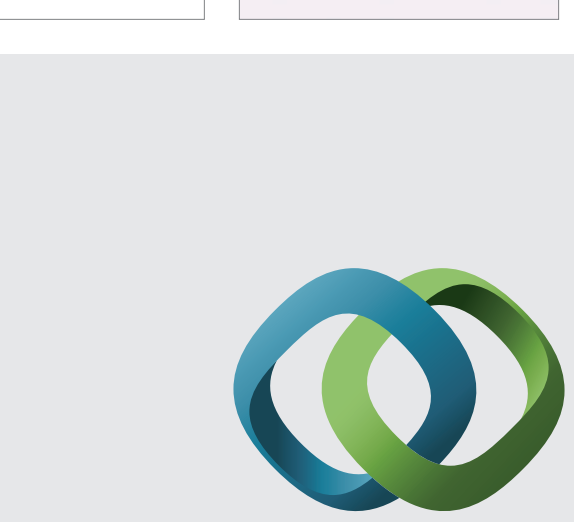

\section{Hindawi}

Submit your manuscripts at

http://www.hindawi.com
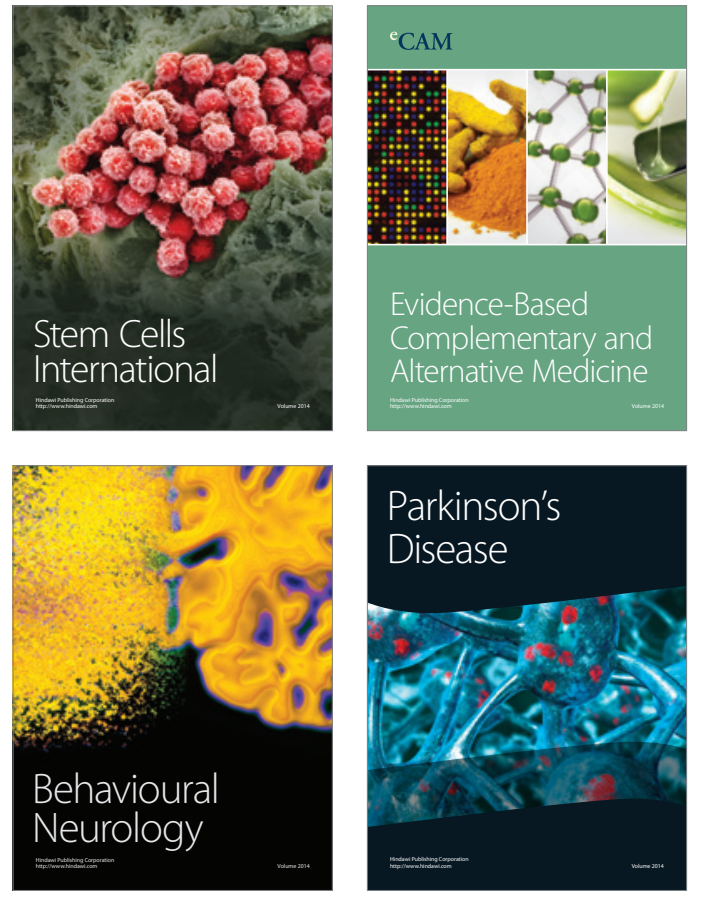
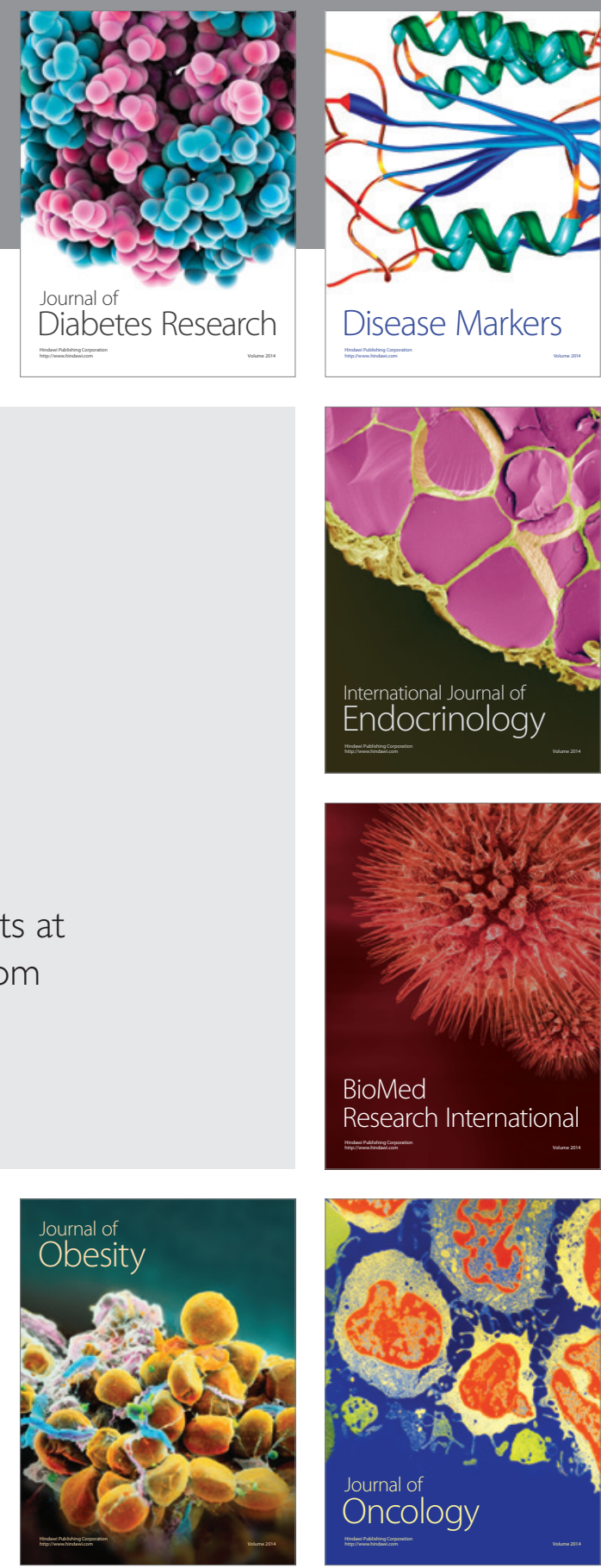

Disease Markers
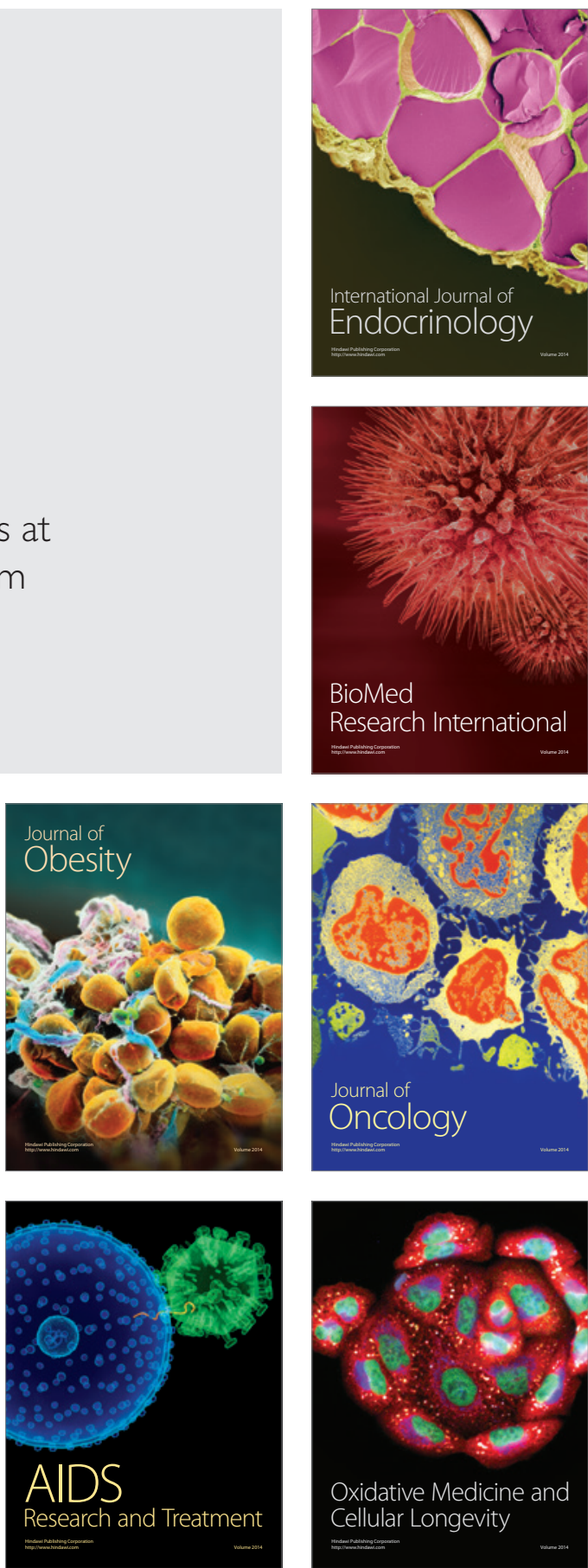